Available online at http://docs.lib.purdue.edu/jate

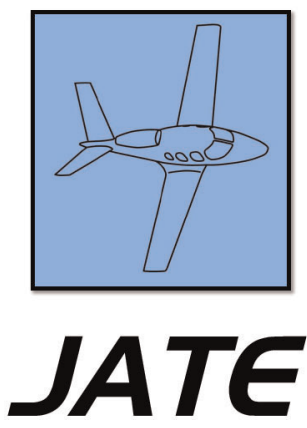

Journal of Aviation Technology and Engineering 6:1 (2016) 64-89

\title{
Pilot Source Study 2015: An Analysis of FAR Part 121 Pilots Hired after Public Law 111-216-Their Backgrounds and Subsequent Successes in US Regional Airline Training and Operating Experience
}

\author{
Guy Smith
}

Embry Riddle Aeronautical University

\section{Elizabeth Bjerke}

University of North Dakota

\section{MaryJo Smith}

Ypsilon Associates

\section{Cody Christensen}

South Dakota State University

Thomas Carney

Purdue University

\section{Paul Craig}

Middle Tennessee State University

Mary Niemczyk

Arizona State University

\section{Abstract}

This report is the second in a series entitled Pilot Source Study 2015. Public Law 111-216 (Airline Safety and Federal Aviation Administration Extension Act of 2010) and the subsequent FAA regulation changed pilot hiring for US air carriers operating under 14 CFR Part 121. The Pilot Source Study 2015 was designed to determine the effect of Public Law 111-216 on US regional airlines after 
its effective date, August 1, 2013. The study collected records for 6,734 FAR Part 121 regional airline pilots to determine the effect of pilots' backgrounds on their performance in regional airline training and operations. A previous report (Bjerke et al., 2016) compared the backgrounds of these pilots (post-law pilots) to the backgrounds of pilots hired between 2005 and 2011 (pre-law pilots). This report examines the performance of post-law new-hire pilots in initial training and operations as first officers for Part 121 regional air carriers. Post-law pilot backgrounds were measured against four performance measures: non-completions, extra training, extra initial operating experience (IOE), and extra recurrent training. Pilots who had the fewest non-completions and required less extra training were the recent college graduates (fewer than 4 years since graduation), pilots with fewer total flight hours (1,500 hours or less), and pilots who graduated from flight programs accredited by the Aviation Accreditation Board International (AABI). Pilots who required less extra IOE and less extra recurrent training were pilots whose previous employment was with a Part 121 air carrier, recent college graduates (fewer than 4 years since graduation), and pilots with fewer total flight hours (1,500 hours or less). Other background indicators of successful performance included the Institutional-Authority Restricted ATP (R-ATP); a bachelor's degree, particularly in aviation; and prior military pilot experience. The third report of this series will compare background and success factors between pre-law pilots and post-law pilots.

Keywords: Pilot Source Study, Public Law 111-216, pilot certification and qualification requirements for air carrier operations, FOQ Rule, 14 CFR Part 121, ATP, R-ATP, pilot hiring, pilot training, first officer, transportation law, Airline Safety and Federal Aviation Administration Extension Act, airline pilot, new-hire pilot, flight hours, AABI, operating experience, recurrent training, regional airline, CFI, flight instructor

\section{Introduction}

Historically, airline accidents have often become catalysts for change within the aviation industry; media attention leads to public attention that, in turn, often leads to legislative actions that precipitate these industry changes. The Federal Aviation Administration (FAA) arose from the ashes of the 1956 Grand Canyon midair collision between United Airlines Flight 718 and TWA Flight 2 that killed all 128 aboard both aircraft (Simpson, 2014). In modern times, Public Law 111-216, the Airline Safety and Federal Aviation Administration Extension Act of 2010, was unanimously passed by Congress in the aftermath of the 2009 crash of Colgan Air Flight 3407 (National Transportation Safety Board [NTSB], 2010). Three years later, on August 1, 2013, Public Law 111-216 and the resulting FAA (2013, July 15) regulation, Pilot Certification and Qualification Requirements for Air Carrier Operations, went into full effect. The new law suspended career opportunities for some low-time pilots and created challenges for airlines (particularly regional airlines) to find qualified applicants for cockpit crewmember positions. Previously, air carriers certificated under 14 CFR Part 121 (Operating Requirements: Domestic, Flag, and Supplemental Operations, 2015) could employ first officers who held a Commercial Pilot certificate without any minimum age requirement or specified minimum flight hours beyond the requirements for the Commercial Pilot certificate. The new law dramatically changed the requirements for entry-level air carrier pilots; it required first officers to possess the Air Transport Pilot (ATP) certificate with minimums of 1,500 flight hours and 23 years of age. Some exemptions or "restricted privileges" were granted to prior military pilots who had at least 750 total flight hours, graduates from specified aviation bachelor's degree programs with at least 1,000 total flight hours, and graduates from specified aviation associate or bachelor's degree programs with at least 1,250 hours of total flight time (FAA, 2013, July 15).

In two previous studies, Pilot Source Study researchers examined the source characteristics (background) and subsequent performance of entry-level first officers in Part 121 air carrier training and operations (Smith, Bjerke, NewMyer, Niemczyk, \& Hamilton, 2010; Smith et al., 2013). During the summer of 2015, when Public Law 111-216 and the FAA authorizations had been in place for two years, the Pilot Source Study researchers were asked to reexamine the background, qualifications, and performance of new first officers (post-law pilots hired after the August 1, 2013 effective date of Public Law 111-216). To support this effort, members of the research team traveled across the US from April to October, 2015, and visited 19 Part 121 regional airlines and 3 Part 135 regional airlines. Extensive background, training, and operating data were collected from the airline records of over 7,000 pilots hired since the new law took effect. The resulting effort represents the largest and most detailed investigation of entry-level airline pilots that has been conducted to date. This article is the second in a series of reports on those datasets, collectively known as the Pilot Source Study 2015.

In the first report of Pilot Source Study 2015 (Bjerke et al., 2016), the researchers described the backgrounds of pilots hired by the 19 Part 121 regional airlines since August 1, 2013-the date Public Law 111-216 became effective. The first report detailed the backgrounds of airline pilots hired in the post-law era and compared their backgrounds to those of pilots hired in the pre-law era. This second report in the series is an examination of the performance of the post-law new-hire pilots as they began their airline careers, following them from their initial airline training through becoming fully qualified regional airline pilots. This study documents pilot performance during training events in the classroom, flight training devices, and 
full-flight simulators and continues to document pilot performance after training culminated in initial operating experience (IOE) or operating experience (OE) in the aircraft. At the completion of IOE or OE, trainees become fully qualified line pilots and this study continues to record their performance in any line checks or recurrent training events that were documented.

Data collected for all Pilot Source Studies came solely from airline records; no pilots were contacted, interviewed, or surveyed. It is important to note that airlines are not required to maintain detailed records of individual pilot performance; thus, information in airline training records differs widely. Many airlines retain only the minimum information required by the FAA. As a result, when data from several airlines are combined into one dataset, much of the individual detail is lost because there is no uniformity among the airlines' training records. Thus, paucity of data is sometimes a deterrent to comprehensive data collection and analysis. The FAA's Advanced Qualification Program (AQP) (FAA, 2006, 2015b) is a data-driven method of qualifying and certifying pilots; $\mathrm{AQP}$ is designed to provide plentiful, uniform data that could fulfill the needs of the Pilot Source Study. During data collection, the researchers experienced two aspects of the AQP that hampered data collection:

- Most of the regional airlines did not use the AQP for initial qualification of pilots, opting instead to employ the traditional requirements of $14 \mathrm{CFR}$ Part 121, Subpart N and O and Appendices E and F (Operating Requirements: Domestic, Flag, and Supplemental Operations, 2015). Some of the regional airlines used the AQP for recurrent training (continuing qualification).

- Airlines collect individual pilot performance data; however, the data maintained and reported to the FAA are de-identified for program monitoring, not for individual pilot monitoring (FAA, 2006).

\section{Research Question}

The first report of Pilot Source Study 2015 (Bjerke et al., 2016) described the backgrounds of the post-law pilots. This second report analyzes the performance of those pilots in airline training and operating experience to determine whether there is a difference in performance, based on pilots' backgrounds. Statistical analyses were conducted to determine which pilot backgrounds yielded the greatest success. Thus, this study aims to answer the following research question:

- How do the background (source) characteristics of post-law pilots affect their performance (outcomes) at a Part 121 regional airline (i.e., non-completions, extra training, extra IOE, and extra recurrent training)?

\section{Review of the Literature}

All airline accidents result in increased scrutiny from the flying public, media, Department of Transportation, Federal Aviation Administration, and Congress, among others (Depperschmidt, Bliss, \& Casebolt, 2015). During the last decade, three high-profile accidents occurred involving Part 121 air carrier operations at regional airlines: Pinnacle Airlines Flight 3701 (NTSB, 2007a), Comair Flight 5191 (NTSB, 2007b), and most notably Colgan Air Flight 3407 (NTSB, 2010) that resulted in loss of life of passengers, crew, and persons on the ground. All three of these accidents were attributed to pilot error, and they became catalysts for changes to regulations focusing on pilot qualifications and training (NTSB, 2007a, 2007b, 2010).

\section{Reflections on Previous Studies, Pre-Law}

In response to the crash of Colgan Air Flight 3407 (NTSB, 2010), additional rules and regulations were proposed by a number of organizations. When the FAA issued an Advanced Notice of Proposed Rulemaking (ANPRM) requesting public comment on possible changes to pilot certification regulations (FAA, 2010, February 8), it became clear that data and empirical studies would have more effect than anecdotes or opinions. Specifically, a need for empirical data about the backgrounds and experiences of new-hire pilots and how their backgrounds and experiences affected their performance in the regional airlines was identified. Strong beliefs were expressed by many stakeholders that more total flight hours make a pilot more proficient as a required crewmember in Part 121 operations; however, no studies empirically linked total flight hours to pilot performance. With the need identified, the "2010 Pilot Source Study" (Smith et al., 2010) was commissioned to study the source characteristics of airline pilots and to identify those source characteristics that resulted in better performance in regional airline training. The "2010 Pilot Source Study" analyzed 2,156 records, a convenience sample of pilots hired between 2005 and 2009 from six regional airlines. The most important finding from that study was that pilots who accrued between 501 and 1,000 pre-employment flight hours had the fewest extra training events and more completions than their counterparts who had more (or fewer) flight hours.

Shortly after the "2010 Pilot Source Study" (Smith et al., 2010) was published, the FAA issued the Notice of Proposed Rulemaking (NPRM), Pilot Certification and Qualification Requirements for Air Carrier Operations, requesting comments on a proposal to create new certification requirements for pilots in air carrier operations (FAA, 2012, February 29). To effectively respond to the NPRM, it became evident that the data collected for the "2010 Pilot Source Study" were not sufficient. 
The research needed to be expanded to more regional airlines, leading to the "2012 Pilot Source Study" (Smith et al., 2013).

The "2012 Pilot Source Study" (Smith et al., 2013) was an analysis of 4,024 new-hire pilot records, a convenience sample of pilots hired between 2005 and 2011 from seven different regional airlines. Both the "2010 Pilot Source Study" and the "2012 Pilot Source Study" found significant results related to new-hire pilots' backgrounds regarding college degree, aviation degree, graduation from an Aviation Accreditation Board International (AABI) flight program - the source of advanced pilot trainingholding a CFI certificate, and previous experience. The most important findings of both studies were related to total flight hours. The "2010 Pilot Source Study" found that pilots who had between 501 and 1,000 total flight hours had fewer extra training events and more training completions, and the "2012 Pilot Source Study" found that pilots who had between 1,001 and 1,500 total flight hours had more training completions. Notably, the findings from both studies did not support the tenets of the Airline Safety and Federal Aviation Administration Extension Act (Public Law 111-216) that required pilots to have an ATP certificate with a minimum of 1,500 hours to "function effectively" (2010, p. 8), as a Part 121 regional airline pilot.

\section{Public Law 111-216 and the FOQ Rule}

In 2010, the US Congress passed the Airline Safety and Federal Aviation Administration Extension Act of 2010 (Public Law 111-216). Public Law 111-216 and the subsequent FAA regulation, Pilot Certification and Qualification Requirements for Air Carrier Operations Rule (FAA, 2013, July 15), also known as the First Officers Qualification (FOQ) Rule, radically changed pilot hiring criteria for US air carriers operating under 14 CFR Part 121. According to the FOQ Rule, after August 1, 2013, all required crewmembers in air carrier operations must possess an Airline Transport Pilot (ATP) certificate, the highest pilot certificate granted by the FAA (Federal Aviation Administration, 2015c). The ATP requires a pilot to be at least 23 years old and to log at least 1,500 hours of total flight time (FAA, 2013, July 15). The FOQ Rule allowed some age and flight-hour reductions for specific military and FAA-approved post-secondary academic experiences.

In the aftermath of the FOQ Rule, the Restricted Airline Transport Pilot (R-ATP) was created. The R-ATP is a new pilot certificate class that allows an individual to work for a US airline as a required pilot crewmember without meeting the flight time requirements of the International Civil Aviation Organization (ICAO), as prescribed under Article 39 of the Convention on International Civil Aviation ("Aeronautical experience: Airplane category rating," 2015) for a traditional ATP certificate. R-ATP certificated pilots cannot act as pilot-in-command in air carrier Part 121 operations; though they meet the other requirements of Public Law 111-216 for first officers ("Aeronautical experience: Airplane category restricted privileges," 2015).

The FOQ Rule allows the FAA administrator to determine alternative methods of specifically designed training, in lieu of the minimum flight time experience required for the traditional ATP ("Aeronautical experience: Airplane category restricted privileges," 2015). The R-ATP also allows certificated pilots to fly as required crewmembers in air carrier operations at the age of 21 instead of 23. Pilots trained by the US military can meet R-ATP requirements with 750 flight hours, the fewest number of flight hours allowed for the R-ATP requirements. In addition, two additional paths are available for civilian pilots to earn the R-ATP certificate: (a) graduates from an FAA-approved R-ATP bachelor's degree program with at least 60 credits of approved coursework have a reduced total flight hours requirement of 1,000 hours, and (b) graduates from FAAapproved R-ATP associate degree or bachelor's degree programs with at least 30 credits of approved coursework have a reduced total flight hours requirement of 1,250 hours (FAA, 2013, July 12).

\section{Pilot Source Study 2015-First Report}

After Public Law 111-216 had been in effect for about two years, the "Pilot Source Study 2015" was commissioned to assess the effects of Public Law 111-216 on pilot hiring. The first report of the "Pilot Source Study 2015" was a study of the background characteristics of pilots hired after Public Law 111-216 went into effect (Bjerke et al., 2016). As part of this study, descriptive analyses were conducted on the background characteristics of regional airline pilots hired from August 1, 2013 to the date of data collection (defined as "post-law pilots"). The background characteristics of these post-law pilots were compared to the background characteristics of pilots hired between 2005 and 2011 (defined as "pre-law pilots"). In the pre-law dataset $66 \%$ of pilots had an aviation-related degree, while in the post-law dataset only $51 \%$ of the pilots had an aviation-related degree. Similarly, in the pre-law dataset $32 \%$ of pilots had degrees from AABI-accredited flight programs, while only $23 \%$ of the pilots in the post-law dataset had degrees from AABI-accredited flight programs. The first report of the "Pilot Source Study 2015" (Bjerke et al., 2016) also found that a majority of the post-law pilots (approximately 60\%) graduated more than five years ago, indicating that post-law pilots may be returning to a pilot career path after an interruption or that they may be seeking a career change. This result was different from the pre-law pilot source studies' results in which the majority of the newly hired pilots had started in a collegiate or academy flight program and shortly thereafter transitioned to an airline career. Additionally, there were more military pilots 
in the post-law dataset (12\%) than in the pre-law dataset (3\%). As a direct result of Public Law 111-216, pilots in the post-law dataset had more total flight hours. This difference in flight hours was especially notable among hightime pilots; in the pre-law dataset, $9 \%$ of the pilots had more than 3,000 hours; in the post-law dataset $31 \%$ of the pilots had more than 3,000 hours. An interesting finding of the first report of the "Pilot Source Study 2015" was that post-law pilots had significantly fewer multiengine hours, since Public Law 111-216 requires only 50 hours of multiengine time (Bjerke et al., 2016).

\section{Pilot Training}

In order to determine the impact of pilots' background characteristics on their success in initial training and first year of operations at a Part 121 airline, it is important to understand all the associated training requirements. While airlines have variations in their training programs, the training process for initial pilot training must meet or exceed the regulations prescribed by the FAA in Subpart $\mathrm{N}$ and $\mathrm{O}$ and Appendices E and F of 14 CFR Part 121 ("Operating Requirements: Domestic, Flag, and Supplemental Operations," 2015). The first step is the airline interview in which background information for each candidate is gathered. The interview often includes a scrutiny of the pilot's FAA certificates and ratings, flight time breakdown, and education; the purpose is to verify that the pilot meets or exceeds all regulatory requirements.

One of the new requirements mandated by the FOQ Rule is the Airline Transport Pilot Certification Training Program (ATP CTP) (FAA, 2013, July 2). The FAA developed the ATP CTP with the intention of bridging the gap between pilots holding the Commercial Pilot certificate and those holding the ATP, to enable them to operate safely in those operations that require an ATP certificate (Federal Aviation Administration, 2015c). After July 31, 2014, before a pilot can begin training for a Part 121 air carrier, the pilot must present a graduation certificate from an authorized ATP CTP (Training Requirements, 2015). The ATP CTP requires all pilots applying for the R-ATP or traditional ATP to complete 30 hours of academic training and ten hours of simulator training, of which six hours must be in a Level C or higher full flight simulator (FFS) (FAA, 2015c). If the pilot applicant does not have an ATP CTP graduation certificate, the air carrier itself can supply the ATP CTP training program, but that training must be separate from the air carrier's pilot training program ("Airline Transport Pilot Certification Training Program,” 2015).

When the airline determines that a pilot applicant meets all qualifications for hire, the new-hire pilot is given a class date signifying when the pilot will begin training with the airline. An airline can hire pilots with fewer than 1,500 total flight hours, as long as they meet the criteria specified by the R-ATP regulations in 14 CFR 61.160 ("Aeronautical
Experience: Airplane Category Restricted Privileges," 2015). The reduction of required flight hours applies only to first officers; pilots hired with fewer than the required 1,500 total flight hours are not eligible to serve as Pilot-inCommand of a Part 121 aircraft until they have achieved the full ATP certificate (FAA, 2013, July 15).

All regional airlines have their own FAA-approved training curriculum, regulated by Subpart $\mathrm{N}$ and $\mathrm{O}$ and Appendices E and F of 14 CFR Part 121 ("Operating Requirements: Domestic, Flag, and Supplemental Operations," 2015). For initial training, most airlines follow the traditional Part 121 curriculum; a few have transitioned or are transitioning to AQP for initial training (FAA, 2015b). AQP is a data-driven, systematic approach to training and evaluating or validating crewmembers on specific content related to that specific airline. The differences among regional airlines' training programs make it difficult to collect matching data from multiple distinct airlines; each airline has different evaluation, validation, and reporting requirements.

In a typical training program, new-hire pilots complete multiple stages of initial training before they are qualified to fly as crewmembers. The first curriculum is basic indoctrination, which is separated into two general subject areas, one related to operator-specific training and the other to airman-specific training (FAA, 2014, December 30). The operator-specific training includes crew duties and responsibilities, regulations, operations specifications (OpSpecs) and operations manuals, along with hazardous materials training (FAA, 2014, December 30). The airman-specific indoctrination program includes training on operational control, aircraft performance, weight and balance, meteorology, navigation, airspace and ATC procedures, charting and flight planning, instrument procedures, ground operational safety, emergency training, and communication procedures (FAA, 2014, December 30).

After the basic indoctrination curriculum, pilots advance to a ground training curriculum specific to the aircraft they will fly. Ground training includes topics and evaluations over general operations, aircraft systems, knowledge and procedures, emergency situations, flight physiology, and emergency drills (FAA, 2014, December 30). Ground courses may be taught in a traditional classroom setting or they may be taught through computer-based instruction.

The flight training curriculum starts the practical component of the initial training program. The purpose of the flight training curriculum is to acquire the skills and knowledge necessary to perform to a desired standard. Flight training includes procedure training on checklists and flows followed by maneuvers training, usually in a combination of procedure trainers, flight simulation training devices, full flight simulators, or the actual aircraft (FAA, 2015a). This segment of training includes practicing maneuvers, normal and abnormal procedures, and emergency procedures. 
After new-hire pilots demonstrate competency in the knowledge, skills, and abilities of the flight training curriculum, they move to the qualification curriculum, which includes line orientated flight training (LOFT) and special purpose operational training (SPOT). The purpose of the qualification curriculum is to facilitate transitioning the new-hire pilot from the training environment to the operational environment (FAA, 2014, December 30).

Initial operating experience (IOE) or operating experience $(\mathrm{OE})$ is the capstone training designed to consolidate the knowledge and skills learned during the previous phases of training (Operating Experience, 2015). OE can be described as a culminating experience administered by a check pilot who essentially "signs off" on all the training; this is the last step in the training before the new first officer (aka second-in-command) is allowed to fly as a fully functioning required crewmember. According to "Operating Experience" (2015), new second-in-command pilots must perform the duties of a second-in-command under the supervision of an appropriately qualified check pilot for a minimum of 25 hours of $\mathrm{OE}$ before they are a fully qualified crewmembers. The minimum 25 hours may be reduced by up to $50 \%$ for each takeoff and landing accomplished under specific criteria (FAA, 2015a).

During any one of the major phases of training, a pilot might be dismissed or terminated, based on performance. Alternatively, a pilot might self-terminate for a multitude of reasons including performance, health, family issues, opportunities with a different airline, etc.

\section{Methodology}

The first report of the "Pilot Source Study 2015" (Bjerke et al., 2016) described the data collection methods for the post-law dataset in detail. A brief summary of the methodology is repeated in this second report.

The principal investigator (PI) contacted the president or $\mathrm{CEO}$ of each regional airline requesting permission to collect data on their new-hire pilots. Each researcher signed a non-disclosure agreement (NDA) stipulating that only de-identified data would be used in the study. Though originally conceived as a convenience sampling of the airlines that participated in the two previous pilot source studies, the post-law study was so well-accepted by the airlines that it became a population study of virtually all Part 121 US regional airlines. The objective was to collect background and training data for pilots hired by these airlines after Public Law 111-216 went into effect, from August 1, 2013 to the date of data collection.

Data collection for the post-law study was conducted by an on-site PI, accompanied by a trained full-time data collection manager, and assisted on occasion by six other data collectors. Data collection yielded 7,073 records from 22 airlines, collected over a period of seven months from April to October, 2015. Not all of the data collected for the post-law study are included in this report. This report includes 6,734 records from 19 Part 121 airlines. Three other airlines operated under 14 CFR Part 135 or with a Part 135 operation specifications addition to a Part 121 certificate (Great Lakes Airlines, 2016). Data from these three airlines (339 records) were excluded from this second report because the FOQ Rule only pertains to 14 CFR Part 121 operators ("Operating Requirements: Domestic, Flag, and Supplemental Operations," 2015). Data from Part 135 operators will be addressed in a future report.

\section{Results}

\section{Effect Size}

All analyses include significance testing and effect size. Significance testing determines whether a statistically significant difference exists; effect size explains the magnitude of the difference (Biddix, 2016). For the goodness of fit in $2 \times 2$ contingency tables, phi $(\Phi)$ was used to measure effect size. For $\Phi$, a value of 0.1 is considered a small effect, 0.3 a medium effect, and 0.5 a large effect (Zaiontz, 2016). Cramer's $V$ is an extension of the above approach for larger than $2 \times 2$ contingency tables (Zaiontz). Table 1 provides the guidelines for size of the effect based on degrees of freedom.

Table 1

Effect sizes for Cramer's V.

\begin{tabular}{lccc}
\hline $\boldsymbol{d f}$ & Small & Medium & Large \\
\hline 1 & .10 & .30 & .50 \\
2 & .07 & .21 & .35 \\
3 & .06 & .17 & .29 \\
\hline
\end{tabular}

Note. Adapted from Zaiontz (2016).

Effect size ( $\Phi$ or Cramer's $V$ for chi-square; Eta squared $\left(\left(\eta^{2}\right)\right.$ for ANOVA) was included in the reporting of all significant results. Although the significance testing showed that the means were significantly different; the effect sizes were small to modest, meaning that the factor accounted for a small or modest percentage of the relationship between pilots' background data and their outcomes at a regional airline. Small effect sizes were anticipated for this study because, in many cases, the outcome variables (associated with regional airline training) were removed by several years from the background variables (associated with pilot's initial pilot training and pre-airline flying experience). According to Trusty, Thompson, and Petrocelli (2004), "Small effect sizes for very important outcomes can be extremely important, as long as they are replicable" (p. 110).

Outcome Variable: Completions

The dependent variable, Completions, was derived from the recorded variable, Status. Status was divided into four 


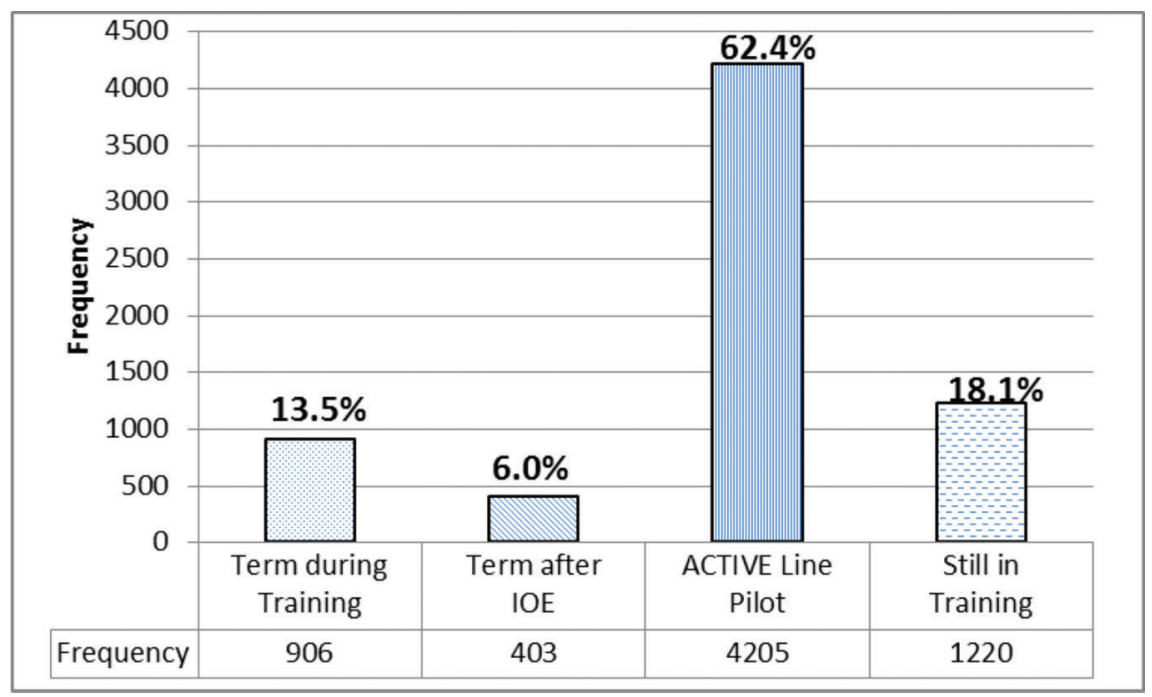

Figure 1. Status of pilots to define Completions and Non-Completions.

groups: Active Line Pilot, Still in Training, Terminated After IOE, and Terminated During Training. An "active line pilot" is a pilot who has successfully completed training, successfully completed IOE (or OE), and was still employed at the time of data collection. A pilot "still in training" is a pilot who has not completed the training and/or IOE and is still employed. Pilots "terminated after IOE" have also successfully completed training and IOE; however, these pilots terminated their employment sometime between IOE and data collection (possibly to seek employment elsewhere). A pilot "terminated during training" was terminated before the training and/or IOE were completed. Pilots may be terminated by the airline for substandard performance; alternatively, the airline may offer a pilot the opportunity to resign in lieu of termination for substandard performance. Pilots also resign for many reasons besides substandard performance-personal reasons, decision to go to a different airline, unfulfilled expectations, family concerns, among others. Generally, the participating airlines did not provide codes that would explain the reason for a pilot's termination; airline managers often questioned whether the reasons given by pilots for termination or resignation were valid. Figure 1 defines Status.

The dichotomous variable, Completions, was derived from Status as follows:

- Active Line Pilots $(4,205)$ and pilots Terminated After IOE (403) were coded as Completions

- Pilots Terminated During Training (906) were coded as Non-Completions

- Pilots Still in Training $(1,220)$ were coded as missing data.

\section{Outcome Variable: Extra Training Events}

In the airlines' training records, Extra Training Events were scores below a passing grade, failed events, repeated events, or any extra training that extended the normal training footprint (Donoghue, 2010). Figure 2 displays the distribution of Extra Training Events as recorded from the pilots' airline training records.

The variable Extra Training Events is exiguous data. Across all airlines, there were unrecorded Extra Training Events because airlines often delete training records or correct deficiencies to $100 \%$. Two categories of Status also yield incomplete Extra Training Events: (a) pilots Still in Training had not yet completed the training, and, by definition, Extra Training Events for these pilots are incomplete data; and (b) pilots Terminated During Training did not complete the training and, by definition, Extra Training Events for these pilots are also incomplete data. In the dataset, Extra Training Events were recorded for 1,966 pilots $(29.2 \%)$. For the planned training footprint, success in each training event is defined as passing the required training on the first attempt (Cortés, 2008); therefore, in this analysis, Extra Training Events is treated as a dichotomous variable (Yes/No).

\section{Outcome Variable: IOE Z-Score}

When pilots complete training, they begin initial operating experience (IOE) or OE, flying the aircraft operationally (with passengers) under the supervision of a captain instructor or check airman. In the dataset, pilots whose Status was Active Line Pilot or Terminated after IOE had IOE hours. Besides the minimum FAA requirements for IOE hours (normally 25), there are operational requirements that dictate the length of time a pilot spends in IOE; many of these requirements are not related to a pilot's performance. Also, airlines have different viewpoints concerning the length of IOE. Therefore, IOE hours were normalized into an IOE Z-score for each airline; the data were then combined across all airlines. Training managers related that it was normal to extend a pilot's IOE beyond the airline's average; however, excessive IOE was more likely to be performance related. Therefore, IOE Z-scores 


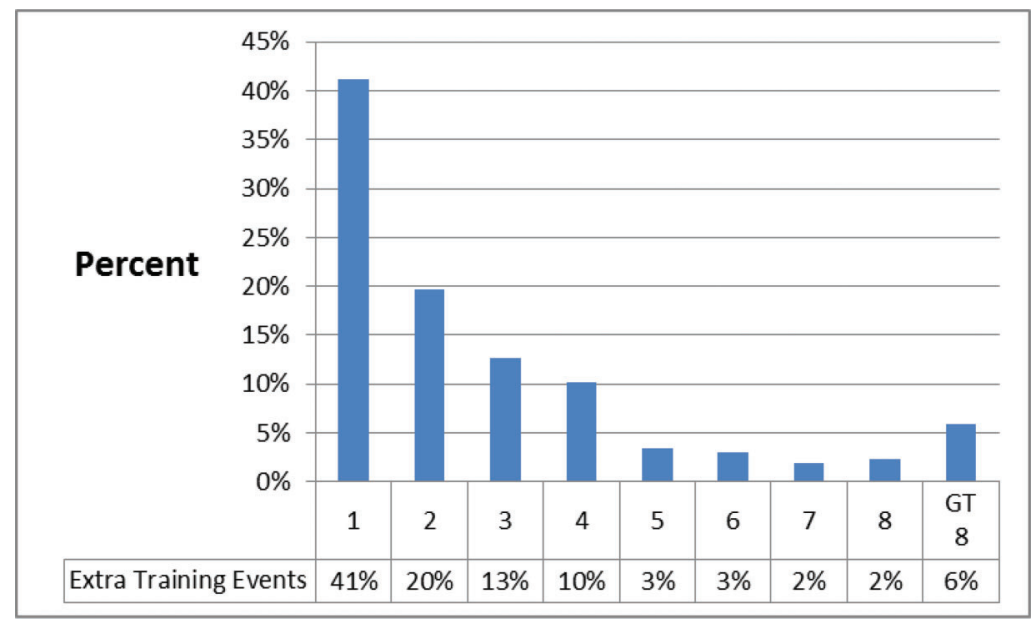

Figure 2. Distribution of Extra Training Events. $N=1,966$ pilots (29.2\% of the dataset).

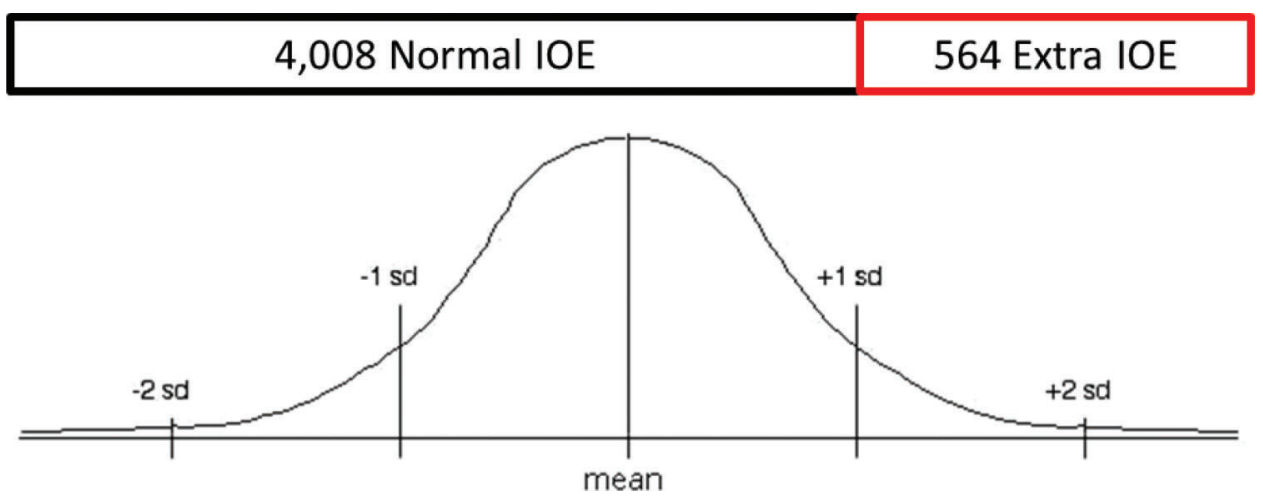

Figure 3. Depiction of IOE. $N=4,572$ pilots ( $68 \%$ of the dataset).

greater than $+1 \mathrm{SD}$ were considered Extra IOE. The IOE $Z$-scores were binned into a dichotomous variable: Normal = +1 SD or less; Extra = more than 1 SD. Figure 3 depicts the distribution of IOE scores.

Outcome Variable: Extra Recurrent

Table 2

Distribution of Extra Recurrent.

\begin{tabular}{lcc}
\hline Number of Extra Recurrent Training Events & Count & Percent \\
\hline One & 215 & $59 \%$ \\
Two & 89 & $24 \%$ \\
Three & 37 & $10 \%$ \\
Four & 14 & $4 \%$ \\
Greater than Four & 12 & $3 \%$ \\
\hline
\end{tabular}

Extra Recurrent is a variable that documents any failed event or extra training that occurred during recurrent training; most of these events were recorded by airlines at which recurrent training was conducted under the Advanced Qualification Program (AQP). Extra Recurrent was recorded for 367 pilots (8\% of Active Line Pilots and Pilots Terminated After IOE). Table 2 displays the distribution of Extra Recurrent. For data analysis, Extra Recurrent is treated as a dichotomous variable (Yes/No).
Predictor Variable: Highest Degree

\begin{tabular}{|c|c|}
\hline \multicolumn{2}{|c|}{ Synopsis-Significant Results for Highest Degree } \\
\hline Positive Outcomes: & $\begin{array}{l}\text { Bachelor's Degree-Fewer Non-Completions; } \\
\text { less Extra Training }\end{array}$ \\
\hline Negative Outcomes: & $\begin{array}{l}\text { High School-More Non-Completions; } \\
\text { more Extra Training } \\
\text { Associate-More Non-Completions; } \\
\text { more Extra Training; more Extra IOE }\end{array}$ \\
\hline
\end{tabular}

In the pilots' background records, 1,214 listed high school diploma as the highest education level attained, 625 had an associate degree, 4,223 had a bachelor's degree, and 539 had a graduate degree. The remaining 133 pilots were missing this predictor variable.

A chi-square test of significance compared Completions based on highest level of education recorded. Significant results $\left(N=5,408(80 \%), \chi^{2}(3)=88.978, p<.001\right.$, Cramer's $V=.128$ ) are displayed in Table 3. Pilots who had a high school diploma or an associate degree had significantly more Non-Completions than expected. Pilots who had a bachelor's degree had significantly fewer NonCompletions than expected. 
Table 3

Comparison of outcomes based on Highest Degree.

\begin{tabular}{|c|c|c|c|c|c|c|}
\hline \multirow{2}{*}{$\begin{array}{l}\text { Highest } \\
\text { Degree }\end{array}$} & \multicolumn{3}{|c|}{ Non-Completions-Positive Outcome } & \multicolumn{3}{|c|}{ Non-Completions-Negative Outcome } \\
\hline & Observed & Expected & $\chi^{2}$ Contribution & Observed & Expected & $\chi^{2}$ Contribution \\
\hline High School & - & - & - & 221 & 161.4 & $29 \%$ \\
\hline Associate & - & - & - & 127 & 83.4 & $29 \%$ \\
\hline \multirow[t]{2}{*}{ Bachelor's } & 443 & 563 & $26 \%$ & - & - & - \\
\hline & \multicolumn{3}{|c|}{ Extra Training-Positive Outcome } & \multicolumn{3}{|c|}{ Extra Training-Negative Outcome } \\
\hline High School & - & - & - & 376 & 337.4 & $17 \%$ \\
\hline Associate & - & - & - & 207 & 172 & $27 \%$ \\
\hline \multirow[t]{2}{*}{ Bachelor's } & 1186 & 1264 & $18 \%$ & - & - & - \\
\hline & \multicolumn{3}{|c|}{ Extra IOE-Positive Outcome } & \multicolumn{3}{|c|}{ Extra IOE-Negative Outcome } \\
\hline Associate & - & - & - & 73 & 47.8 & $76 \%$ \\
\hline
\end{tabular}

A chi-square test of significance compared Extra Training Events based on highest level of education recorded. Significant results $\left(N=5,022(75 \%), \chi^{2}(3)=26.719\right.$, $p<.001$, Cramer's $V=.073)$ are displayed in Table 3. Pilots who had a high school diploma or an associate degree required significantly more Extra Training Events than expected. Pilots who had a bachelor's degree required significantly fewer Extra Training Events than expected.

A chi-square test of significance compared Extra IOE based on highest level of education recorded. Significant results $\left[N=4,497(67 \%), \chi^{2}(3)=17.474, p=.001\right.$, Cramer's $V=.062]$ are displayed in Table 3. Pilots who had an associate degree required significantly more Extra $I O E$ than expected.

A chi-square test of significance compared Extra Recurrent Training based on highest level of education recorded. The results were not significant $[N=4,531(67.3 \%)$, $\chi^{2}(3)=6.762, p=.080$, Cramer's $\left.V=.039\right]$. No significant difference was found for Extra Recurrent Training based on highest level of education recorded.

\section{Predictor Variable: AABI-Accredited Flight Program}

\section{Synopsis-Significant Results for AABI-Accredited Flight Program \\ Positive Outcomes: AABI-accredited flight program-fewer Non-Completions; less Extra Training; less Extra IOE; less Extra Recurrent Training}

Negative Outcomes: None

Of the 6,734 pilots in the dataset, 1,527 graduated from AABI-Accredited Flight Programs. [Note: There are 28 institutions worldwide that have AABI-accredited flight programs (AABI, 2016).] The remaining 5,207 pilots did not graduate from AABI-Accredited Flight Programs.

A chi-square test of significance compared Completions based on graduating from an AABI-Accredited Flight Program. Significant results $\left[N=5,519(82 \%), \chi^{2}(1)=\right.$ 59.654, $p<.001, \Phi=.104]$ are displayed in Table 4 .
Pilots who graduated from AABI-Accredited Flight programs had significantly fewer Non-Completions than expected.

A chi-square test of significance compared Extra Training Events based on graduating from an AABI-Accredited Flight Program. Significant results $[N=5,118$ (76\%), $\left.\chi^{2}(1)=79.403, p<.001, \Phi=.125\right]$ are displayed in Table 4. Pilots who graduated from AABI-Accredited Flight Programs required significantly fewer Extra Training Events than expected.

A chi-square test of significance compared Extra IOE based on graduating from an AABI-Accredited Flight Program. Significant results $\left[N=4,572(68 \%), \chi^{2}(1)=\right.$ 13.992, $p<.001, \Phi=.055]$ are displayed in Table 4 . Pilots who graduated from AABI-Accredited Flight Programs required significantly less Extra IOE than expected.

A chi-square test of significance compared Extra Recurrent Training based on graduating from an AABI-Accredited Flight Program. Significant results $[N=4,613$ (69\%), $\left.\chi^{2}(1)=7.659, p=.006, \Phi=.041\right]$ are displayed in Table 4. Pilots who graduated from AABI-Accredited Flight Programs required significantly less Extra Recurrent Training than expected.

\section{Predictor Variable: Aviation-Related Degree}

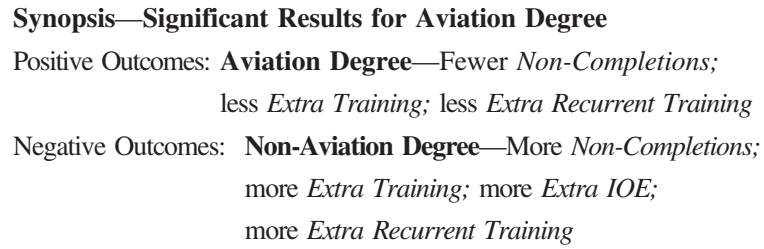

In the dataset, 3,263 pilots $(48 \%)$ were recorded as having an Aviation-Related Degree. This variable is complex; it includes graduates from AABI-Accredited Flight Programs $(N=1,527)$, graduates from non-AABI-Accredited Flight Programs, and graduates from aviation-related (non-flight) programs such as aviation management, air 
Table 4

Comparison of outcomes based on graduating from AABI-Accredited Flight Programs.

\begin{tabular}{|c|c|c|c|c|c|c|}
\hline \multirow{2}{*}{$\begin{array}{l}\text { AABI } \\
\text { Flight }\end{array}$} & \multicolumn{3}{|c|}{ Non-Completions-Positive Outcome } & \multicolumn{3}{|c|}{ Non-Completions-Negative Outcome } \\
\hline & Observed & Expected & $\chi^{2}$ Contribution & Observed & Expected & $\chi^{2}$ Contribution \\
\hline \multirow[t]{2}{*}{ Yes } & 120 & 209.6 & $64 \%$ & - & - & - \\
\hline & \multicolumn{3}{|c|}{ Extra Training-Positive Outcome } & \multicolumn{3}{|c|}{ Extra Training-Negative Outcome } \\
\hline \multirow[t]{2}{*}{ Yes } & 340 & 472.5 & $47 \%$ & - & - & - \\
\hline & \multicolumn{3}{|c|}{ Extra IOE-Positive Outcome } & \multicolumn{3}{|c|}{ Extra IOE-Negative Outcome } \\
\hline \multirow[t]{2}{*}{ Yes } & 106 & 142.1 & $66 \%$ & - & - & - \\
\hline & \multicolumn{3}{|c|}{ Extra Recurrent-Positive Outcome } & \multicolumn{3}{|c|}{ Extra Recurrent-Negative Outcome } \\
\hline Yes & 70 & 92 & $69 \%$ & - & - & - \\
\hline
\end{tabular}

Table 5

Comparison of outcomes for pilots with an Aviation-Related Degree.

\begin{tabular}{|c|c|c|c|c|c|c|}
\hline \multirow{2}{*}{$\begin{array}{l}\text { Aviation } \\
\text { Degree }\end{array}$} & \multicolumn{3}{|c|}{ Non-Completions-Positive Outcome } & \multicolumn{3}{|c|}{ Non-Completions-Negative Outcome } \\
\hline & Observed & Expected & $\chi^{2}$ Contribution & Observed & Expected & $\chi^{2}$ Contribution \\
\hline No & - & - & - & 534 & 430.8 & $42 \%$ \\
\hline \multirow[t]{2}{*}{ Yes } & 338 & 441.2 & $41 \%$ & - & - & - \\
\hline & \multicolumn{3}{|c|}{ Extra Training-Positive Outcome } & \multicolumn{3}{|c|}{ Extra Training-Negative Outcome } \\
\hline No & - & - & - & 1023 & 903.1 & $32 \%$ \\
\hline \multirow[t]{2}{*}{ Yes } & 850 & 969.9 & $30 \%$ & - & - & - \\
\hline & \multicolumn{3}{|c|}{ Extra IOE-Positive Outcome } & \multicolumn{3}{|c|}{ Extra IOE-Negative Outcome } \\
\hline \multirow[t]{2}{*}{ No } & & & & 278 & 251.3 & $47 \%$ \\
\hline & \multicolumn{3}{|c|}{ Extra Recurrent-Positive Outcome } & \multicolumn{3}{|c|}{ Extra Recurrent-Negative Outcome } \\
\hline No & - & - & - & 204 & 168.1 & $49 \%$ \\
\hline Yes & 153 & 188.9 & $43 \%$ & - & - & - \\
\hline
\end{tabular}

traffic control, aviation maintenance, aeronautical engineering, etc.

A chi-square test of significance compared Completions based on whether a pilot had an Aviation-Related Degree. Significant results $\left[N=5,320(79 \%), \chi^{2}(1)=58.491\right.$, $p<.001, \Phi=.105$ ] are displayed in Table 5. Pilots who did not have an aviation-related degree had significantly more Non-Completions than expected; pilots who had an Aviation-Related Degree had significantly fewer NonCompletions than expected.

A chi-square test of significance compared Extra Training Events based on whether a pilot had an Aviation-Related Degree. Significant results $[N=4,930$ (73\%), $\left.\chi^{2}(1)=49.603, p<.001, \Phi=.100\right]$ are displayed in Table 5. Pilots who did not have an Aviation-Related Degree required significantly more Extra Training Events than expected; pilots who had an Aviation-Related Degree required significantly fewer Extra Training Events than expected.

A chi-square test of significance compared Extra IOE based on whether a pilot had an Aviation-Related Degree.
Significant results $\left[N=4,409(65 \%), \chi^{2}(1)=6.087\right.$, $p=.014, \Phi=.037]$ are displayed in Table 5. Pilots who did not have an Aviation-Related Degree required significantly more Extra IOE than expected.

A chi-square test of significance compared Extra Recurrent Training based on whether a pilot had an AviationRelated Degree. Significant results $[N=4,448$ (66\%), $\left.\chi^{2}(1)=15.784, p<.001, \Phi=.060\right]$ are displayed in Table 5. Pilots who did not have an Aviation-Related Degree required significantly more Extra Recurrent Training than expected; pilots who had an Aviation-Related Degree required significantly less Extra Recurrent Training than expected.

Predictor Variable: College Grade Point Average (GPA)

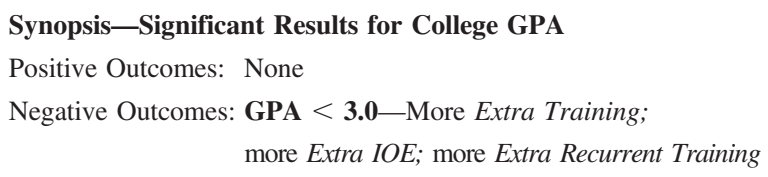


Table 6

Comparison of outcomes based on GPA.

\begin{tabular}{|c|c|c|c|c|c|c|}
\hline \multirow[b]{2}{*}{ GPA } & \multicolumn{3}{|c|}{ Extra Training-Positive Outcome } & \multicolumn{3}{|c|}{ Extra Training-Negative Outcome } \\
\hline & Observed & Expected & $\chi^{2}$ Contribution & Observed & Expected & $\chi^{2}$ Contribution \\
\hline \multirow[t]{2}{*}{ Min to 3.0} & - & - & - & 197 & 171.6 & $48 \%$ \\
\hline & \multicolumn{3}{|c|}{ Extra IOE-Positive Outcome } & \multicolumn{3}{|c|}{ Extra IOE-Negative Outcome } \\
\hline \multirow[t]{2}{*}{ Min to 3.0} & - & - & - & 64 & 50.3 & $66 \%$ \\
\hline & \multicolumn{3}{|c|}{ Extra Recurrent-Positive Outcome } & \multicolumn{3}{|c|}{ Extra Recurrent-Negative Outcome } \\
\hline Min to 3.0 & - & - & - & 51 & 39.2 & $67 \%$ \\
\hline
\end{tabular}

The dataset contains GPA information for 2,527 pilots (38\% of the dataset). Satisfactory GPAs typically range from 2.0 to 4.0, and a GPA of 3.01 and above indicates a high level of success (grade "B" or higher). GPA was usually collected from pilots' résumés. Since résumés are unofficial documents, pilots may not have reported GPA unless they believed it helped to make them more employable. GPA was divided into two categories: minimum to 3.0 (671 pilots), and 3.01 to maximum (1,856 pilots).

A chi-square test of significance compared Completions based on GPA. The results were not significant $[N=2,043$ (30\%), $\left.\chi^{2}(1)=2.850, p=.091, \Phi=.037\right]$. No significant difference was found in Completions based on GPA.

A chi-square test of significance compared Extra Training Events based on GPA. Significant results $[N=1,874$ $\left.(28 \%), \chi^{2}(1)=7.822, p=.005, \Phi=.065\right]$ are displayed in Table 6. Pilots with a GPA of 3.0 or lower required significantly more Extra Training Events than expected.

A chi-square test of significance compared Extra IOE based on GPA. Significant results $[N=1,711(25 \%)$, $\left.\chi^{2}(1)=5.720, p=.017, \Phi=.058\right]$ are displayed in Table 6. Pilots with a GPA of 3.0 or lower required more Extra IOE than expected.

A chi-square test of significance compared Extra Recurrent Training based on GPA. Significant results $[N=1,724$ (26\%), $\left.\chi^{2}(1)=5.228, p=.022, \Phi=.055\right]$ are displayed in Table 6. Pilots with a GPA of 3.0 or lower required significantly more Extra Recurrent Training than expected.

\section{Predictor Variable: Years Since Graduation}

Synopsis-Significant Results for Years Since Graduation
Positive Outcomes: $\leq \mathbf{4}$ Years Since Graduation-Fewer
Non-Completions; less Extra Training;
less Extra Recurrent Training
Negative Outcomes: $>\mathbf{1 0}$ Years Since Graduation-More
more Extra IOE; more Extra Recurrent Training

In the dataset, Year of Graduation was recorded for 3,677 pilots (55\%). Year of Graduation was transformed into Years Since Graduation (based on 2015). Years Since Graduation was divided into three categories: less than or equal to 4 years since graduation, 4 to 10 years since graduation, and greater than 10 years since graduation.

A chi-square test of significance compared Completions based on Years Since Graduation. Significant results $\left[N=2,998(45 \%), \chi^{2}(2)=200.997, p<.001\right.$, Cramer's $V=.259)]$ are displayed in Table 7. Pilots who graduated from college more than 10 years ago had significantly more Non-Completions than expected. Pilots who graduated in the last four years had significantly fewer Non-Completions than expected.

A chi-square test of significance compared Extra Training Events based on Years Since Graduation. Significant results $\left[N=2,753(41 \%), \chi^{2}(2)=67.888, p<.001\right.$, Cramer's $V=.157$ ] are displayed in Table 7. Pilots who graduated from college more than 10 years ago required significantly more Extra Training Events than expected. Pilots who graduated in the last four years required significantly fewer Extra Training Events than expected.

A chi-square test of significance compared Extra IOE based on Years Since Graduation. Significant results $(N=$ $2,480(37 \%), \chi^{2}(2)=12.877, p=.002$, Cramer's $V=$ .072 ) are displayed in Table 7. Pilots who graduated from college more than 10 years ago required significantly more Extra IOE than expected.

A chi-square test of significance compared Extra Recurrent Training based on Years Since Graduation. Significant results $\left[N=2,495(37 \%), \chi^{2}(2)=17.613, p<.001\right.$, Cramer's $V=.084$ ] are displayed in Table 7. Pilots who graduated from college more than 10 years ago required significantly more Extra Recurrent Training than expected. Pilots who graduated from college fewer than four years ago required significantly less Extra Recurrent Training than expected. 
Table 7

Comparison of outcomes based on Years Since Graduation.

\begin{tabular}{|c|c|c|c|c|c|c|}
\hline \multirow{2}{*}{$\begin{array}{l}\text { Years Since } \\
\text { Graduation }\end{array}$} & \multicolumn{3}{|c|}{ Non-Completions-Positive Outcome } & \multicolumn{3}{|c|}{ Non-Completions-Negative Outcome } \\
\hline & Observed & Expected & $\chi^{2}$ Contribution & Observed & Expected & $\chi^{2}$ Contribution \\
\hline$\leq 4$ Yrs. & 65 & 165.4 & $30 \%$ & - & - & - \\
\hline \multirow[t]{2}{*}{$>10$ Yrs. } & - & - & - & 303 & 171.6 & $50 \%$ \\
\hline & \multicolumn{3}{|c|}{ Extra Training-Positive Outcome } & \multicolumn{3}{|c|}{ Extra Training-Negative Outcome } \\
\hline$\leq 4$ Yrs. & 284 & 354.8 & $21 \%$ & - & - & - \\
\hline \multirow[t]{2}{*}{$>10$ Yrs. } & - & - & - & 409 & 315.9 & $40 \%$ \\
\hline & \multicolumn{3}{|c|}{ Extra IOE-Positive Outcome } & \multicolumn{3}{|c|}{ Extra IOE-Negative Outcome } \\
\hline \multirow[t]{2}{*}{$>10$ Yrs. } & - & - & - & 111 & 85.0 & $62 \%$ \\
\hline & \multicolumn{3}{|c|}{ Extra Recurrent-Positive Outcome } & \multicolumn{3}{|c|}{ Extra Recurrent-Negative Outcome } \\
\hline$\leq 4$ Yrs. & 44 & 63.1 & $33 \%$ & - & - & - \\
\hline$>10$ Yrs. & - & - & - & 72 & 49.3 & $59 \%$ \\
\hline
\end{tabular}

Table 8

Comparison of outcomes based on Predominant Employment.

\begin{tabular}{|c|c|c|c|c|c|c|}
\hline \multirow{2}{*}{$\begin{array}{l}\text { Predominant } \\
\text { Employment }\end{array}$} & \multicolumn{3}{|c|}{ Non-Completions-Positive Outcome } & \multicolumn{3}{|c|}{ Non-Completions-Negative Outcome } \\
\hline & Observed & Expected & $\chi^{2}$ Contribution & Observed & Expected & $\chi^{2}$ Contribution \\
\hline Flt Instructor & 276 & 323.5 & $27 \%$ & - & - & - \\
\hline \multirow[t]{2}{*}{ Part 91} & - & - & - & 86 & 66.3 & $23 \%$ \\
\hline & \multicolumn{3}{|c|}{ Extra Training-Positive Outcome } & \multicolumn{3}{|c|}{ Extra Training_-Negative Outcome } \\
\hline Part 121 & 427 & 515.9 & $28 \%$ & - & - & - \\
\hline \multirow[t]{2}{*}{ Part 91} & - & - & - & 174 & 141.7 & $13 \%$ \\
\hline & \multicolumn{3}{|c|}{ Extra IOE-Positive Outcome } & \multicolumn{3}{|c|}{ Extra IOE-Negative Outcome } \\
\hline Flt Instructor & - & - & - & 279 & 211.4 & $33 \%$ \\
\hline \multirow[t]{2}{*}{ Part 121} & 81 & 150 & $48 \%$ & - & - & - \\
\hline & \multicolumn{3}{|c|}{ Extra Recurrent-Positive Outcome } & \multicolumn{3}{|c|}{ Extra Recurrent-Negative Outcome } \\
\hline Flt Instructor & - & - & - & 166 & 134 & $24 \%$ \\
\hline Part 121 & 58 & 95 & $45 \%$ & - & - & - \\
\hline
\end{tabular}

Predictor Variable: Predominant Employment

Synopsis-Significant Results for Predominant Employment
Positive Outcomes: Flight Instructor-Fewer Non-Completions
Part 121-less Extra Training; less Extra
IOE; less Extra Recurrent Training
Negative Outcomes: Part 91-More Non-Completions;
more Extra Training
Flight Instructor-More Extra IOE;
more Extra Recurrent Training

In applications or résumés, pilots listed their previous employments - a vast assortment of experiences. From each list, the data collectors selected the work that appeared to be a pilot's predominant employment. These various employments were divided into nine categories: Flight
Instructor, Military Pilot, Other Aviation Profession, NonAviation Profession, Part 121, Part 135, Part 91, Foreign Pilot, and Unknown. For the chi-square calculation, four of these categories (Other Aviation Profession, Non-Aviation Profession, Foreign Pilot, and Unknown) were considered missing data because their small numbers violated the assumptions of the chi-square.

A chi-square test of significance compared Completions based on Predominant Employment. Significant results $\left[N=5,306(79 \%), \chi^{2}(4)=25.440, p<.001\right.$, Cramer's $V=.069$ ] are displayed in Table 8. Pilots whose Predominant Employment was Flight Instructor had significantly fewer Non-Completions than expected; pilots whose Predominant Employment was Part 91 had more NonCompletions than expected.

A chi-square test of significance compared Extra Training Events based on Predominant Employment. Significant 
Table 9

Comparison of outcomes between CFIs and non-CFIs.

\begin{tabular}{|c|c|c|c|c|c|c|}
\hline \multirow[b]{2}{*}{ CFI } & \multicolumn{3}{|c|}{ Non-Completions-Positive Outcome } & \multicolumn{3}{|c|}{ Non-Completions-Negative Outcome } \\
\hline & Observed & Expected & $\chi^{2}$ Contribution & Observed & Expected & $\chi^{2}$ Contribution \\
\hline \multirow[t]{2}{*}{ No } & - & - & - & 283 & 195.5 & $66 \%$ \\
\hline & \multicolumn{3}{|c|}{ Extra Training-Positive Outcome } & \multicolumn{3}{|c|}{ Extra Training-Negative Outcome } \\
\hline No & - & - & - & 460 & 404.5 & $49 \%$ \\
\hline
\end{tabular}

results $\left[N=4,926(73 \%), \chi^{2}(4)=55.101, p<.001\right.$, Cramer's $V=.106]$ are displayed in Table 8. Pilots whose Predominant Employment was Part 121 required significantly fewer Extra Training Events than expected; pilots whose Predominant Employment was Part 91 required significantly more Extra Training Events than expected.

A chi-square test of significance compared Extra IOE based on Predominant Employment. Significant results $\left[N=4,412(66 \%), \chi^{2}(4)=65.788, p<.001\right.$, Cramer's $V=.122]$ are displayed in Table 8. Pilots whose Predominant Employment was Part 121 required significantly less Extra IOE than expected; pilots whose Predominant Employment was Flight Instructor required significantly more Extra IOE than expected.

A chi-square test of significance compared Extra Recurrent Training based on Predominant Employment. Significant results $\left[N=4,450(66 \%), \chi^{2}(4)=31.860\right.$, $p<.001$, Cramer's $V=.085$ ] are displayed in Table 8. Pilots whose predominant employment was Part 121 required significantly less Extra Recurrent Training than expected; pilots whose predominant employment was Flight Instructor required significantly more Extra Recurrent Training than expected.

\section{Predictor Variable: CFI Certificate}

Synopsis-Significant Results for CFI Certificate
Positive Outcomes: None
Negative Outcomes: No CFI Certificate-More Non-Completions;
more Extra Training

In the pilot records, 5,225 (78\%) were recorded as Certificated Flight Instructors (CFI). This variable includes all pilots who held CFI Certificates, irrespective of their predominant employment.

A chi-square test of significance compared Completions between pilots who held CFI Certificates and pilots who did not hold CFI Certificates. Significant results $[N=$ 5,519 (82\%), $\left.\chi^{2}(1)=59.723, p<.001, \Phi=.104\right]$ are displayed in Table 9. Pilots who did not hold CFI Certificates had significantly more Non-Completions than expected.

A chi-square test of significance compared Extra Training Events between pilots who held CFI Certificates and pilots who did not hold CFI Certificates. Significant results $\left[N=5,118(76 \%), \chi^{2}(1)=15.571, p<.001, \Phi=\right.$ $.055]$ are displayed in Table 9. Pilots who did not hold CFI certificates required significantly more Extra Training than expected.

A chi-square test of significance compared Extra IOE between pilots who held CFI Certificates and pilots who did not hold CFI Certificates. The results were not significant $\left[N=4,572(68 \%), \chi^{2}(1)=.190, p=.650\right.$, $\Phi=.006]$. No significant difference was found for Extra IOE based on being a CFI Certificate holder.

A chi-square test of significance compared Extra Recurrent Training between pilots who held CFI Certificates and pilots who did not hold CFI Certificates. The results were not significant $\left[N=4,613(69 \%), \chi^{2}(1)=.856, p=.355\right.$, $\Phi=.014]$. No significant difference was found for Extra Recurrent Training based on being a CFI Certificate holder.

\section{Predictor Variable: Military Pilot}

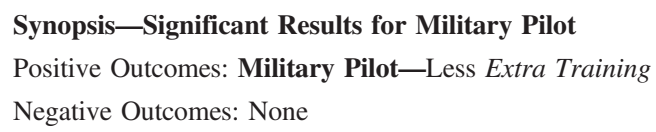

In the dataset, 778 pilots (12\%) had military pilot backgrounds. This variable does not include pilots who served in the military in any status other than pilot.

A chi-square test of significance compared Completions between prior Military Pilots and other pilots. The results were not significant $\left[N=5,391(80 \%), \chi^{2}(1)=1.198\right.$, $p=0.274, \Phi=.015]$. There was no significant difference in Completions between prior Military Pilots and other pilots.

A chi-square test of significance compared Extra Training Events between prior Military Pilots and other pilots. Significant results $\left[N=5,014(74 \%), \chi^{2}(1)=5.272\right.$, $p=.022, \Phi=.032]$ are displayed in Table 10. Prior Military Pilots required significantly fewer Extra Training Events than expected.

A chi-square test of significance compared Extra IOE between prior Military Pilots and other pilots. The results were not significant $\left[N=4,478(66 \%), \chi^{2}(1)=3.062, p=\right.$ $.080, \Phi=.026]$. No significant difference was found for Extra IOE between prior Military Pilots and other pilots. 
Table 10

Comparison of outcomes for prior Military Pilots.

\begin{tabular}{|c|c|c|c|c|c|c|}
\hline \multirow{2}{*}{$\begin{array}{l}\text { Prior Military } \\
\text { Pilot }\end{array}$} & \multicolumn{3}{|c|}{ Extra Training-Positive Outcome } & \multicolumn{3}{|c|}{ Extra Training-Negative Outcome } \\
\hline & Observed & Expected & $\chi^{2}$ Contribution & Observed & Expected & $\chi^{2}$ Contribution \\
\hline Yes & 195 & 220.2 & $55 \%$ & - & - & - \\
\hline
\end{tabular}

Table 11

Comparison of outcomes Based on ATP Certificate.

\begin{tabular}{|c|c|c|c|c|c|c|}
\hline \multirow{2}{*}{$\begin{array}{l}\text { ATP } \\
\text { Certificate }\end{array}$} & \multicolumn{3}{|c|}{ Non-Completions-Positive Outcome } & \multicolumn{3}{|c|}{ Non-Completions-Negative Outcome } \\
\hline & Observed & Expected & $\chi^{2}$ Contribution & Observed & Expected & $\chi^{2}$ Contribution \\
\hline \multirow[t]{2}{*}{ IA R-ATP } & 38 & 136.4 & $68 \%$ & - & - & - \\
\hline & \multicolumn{3}{|c|}{ Extra Training-Positive Outcome } & \multicolumn{3}{|c|}{ Extra Training-Negative Outcome } \\
\hline \multirow[t]{2}{*}{ IA R-ATP } & 242 & 319.2 & $48 \%$ & - & - & - \\
\hline & \multicolumn{3}{|c|}{ Extra Recurrent-Positive Outcome } & \multicolumn{3}{|c|}{ Extra Recurrent-Negative Outcome } \\
\hline IA R-ATP & 41 & 63.1 & $75 \%$ & - & - & - \\
\hline
\end{tabular}

A chi-square test of significance compared Extra Recurrent Training between prior Military Pilots and other pilots. The results were not significant $\left[N=4,519(67 \%), \chi^{2}(1)=\right.$ 2.423, $p=.120, \Phi=.023)]$ No significant difference was found for Extra Recurrent Training between prior Military Pilots and other pilots.

\section{Predictor Variable: ATP Certificate}

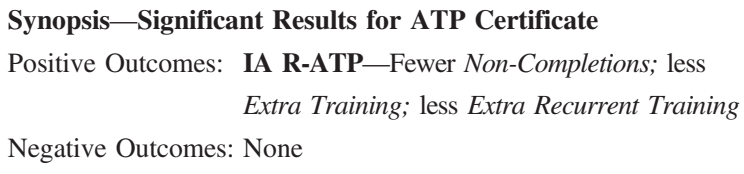

The FOQ Rule (FAA, 2013, July 15) established two types of Restricted ATP Certificates: the Institutional Authority R-ATP (IA R-ATP) and the Military R-ATP (M R-ATP). The 2015 dataset included 1,036 pilots with an IA R-ATP and 141 pilots with an M R-ATP (combined $17 \%$ ). All other pilots had the traditional ATP (23 years old and at least 1,500 hours of total flight time, 500 hours cross-country, 100 hours night, and 75 hours instrument).

A chi-square test of significance compared Completions based on type of ATP Certificate. Significant results $\left(N=5,519(82 \%), \chi^{2}(2)=105.064, p<.001\right.$, Cramer's $V=.138$ ) are displayed in Table 11. Pilots with an IA R-ATP had significantly fewer Non-Completions than expected.

A chi-square test of significance compared Extra Training Events based on type of ATP Certificate. Significant results $\left[N=5,118(76 \%), \chi^{2}(2)=38.693, p<.001\right.$, Cramer's $V=.087$ ] are displayed in Table 11. Pilots with an IA R-ATP required significantly fewer Extra Training Events than expected.
A chi-square test of significance compared Extra IOE based on type of ATP Certificate. The results were not significant $\left[N=4,572(68 \%), \chi^{2}(2)=1.359, \mathrm{p}=.507\right.$, $\Phi=.017]$. No significant difference was found for Extra IOE based on type of ATP Certificate.

A chi-square test of significance compared Extra Recurrent Training based on type of ATP Certificate. Significant results $\left[N=4,613(69 \%), \chi^{2}(2)=10.302, p=.006\right.$, Cramer's $V=.047$ ] are displayed in Table 11. Pilots with an IA R-ATP required significantly less Extra Recurrent Training than expected.

\section{Predictor Variable: Total Flight Hours}

\begin{tabular}{|l}
\hline Synopsis-Significant Results for Total Flight Hours \\
Positive Outcomes: $\leq \mathbf{1 , 5 0 0}$ hours-Fewer Non-Completions; \\
less Extra Training; less Extra Recurrent \\
Training \\
$>\mathbf{4 , 5 0 0}$ hours-Less Extra Recurrent \\
Training \\
Negative Outcomes: $>\mathbf{4 , 5 0 0 ~ h o u r s - M o r e ~ N o n - C o m p l e t i o n s ~}$ \\
$\mathbf{1 , 5 0 1}$ to $\mathbf{3 , 0 0 0}$ Hours-More Extra \\
Recurrent Training
\end{tabular}

The ATP requires a pilot to possess at least 1,500 hours of total flight time; the R-ATP requires fewer than 1,500 hours. Total flight hours were divided into 1,500-hour increments: $\min$ to 1,500 hours $(26.7 \%), 1,501$ to 3,000 hours $(42.1 \%), 3,001$ to 4,500 hours $(13.9 \%)$, and 4,501 to $\max$ hours $(17.3 \%)$.

A chi-square test of significance compared Completions based on the 1,500 Total Flight Hours. Significant results $\left[N=5,465(81 \%), \chi^{2}(3)=160.797, p<.001\right.$, 
Table 12

Comparison of outcomes based on 1,500 Total Flight Hours.

\begin{tabular}{|c|c|c|c|c|c|c|}
\hline \multirow{2}{*}{$\begin{array}{l}\text { Total } \\
\text { Hours }\end{array}$} & \multicolumn{3}{|c|}{ Non-Completions-Positive Outcome } & \multicolumn{3}{|c|}{ Non-Completions-Negative Outcome } \\
\hline & Observed & Expected & $\chi^{2}$ Contribution & Observed & Expected & $\chi^{2}$ Contribution \\
\hline Min to $1500 \mathrm{hrs}$ & 104 & 230.8 & $43 \%$ & - & - & - \\
\hline \multirow[t]{2}{*}{4501 to Max hrs } & - & - & - & 237 & 153.1 & $29 \%$ \\
\hline & \multicolumn{3}{|c|}{ Extra Training-Positive Outcome } & \multicolumn{3}{|c|}{ Extra Training-Negative Outcome } \\
\hline \multirow[t]{2}{*}{ Min to $1500 \mathrm{hrs}$} & 456 & 534.5 & $44 \%$ & - & - & - \\
\hline & \multicolumn{3}{|c|}{ Extra Recurrent-Positive Outcome } & \multicolumn{3}{|c|}{ Extra Recurrent-Negative Outcome } \\
\hline Min to $1500 \mathrm{hrs}$ & 82 & 104.8 & $29 \%$ & - & - & - \\
\hline 1501 to $3000 \mathrm{hrs}$ & - & - & - & 191 & 156.1 & $45 \%$ \\
\hline 4501 to Max hrs & 43 & 56.1 & $18 \%$ & - & - & - \\
\hline
\end{tabular}

Cramer's $V=.172$ ] are displayed in Table 12. Pilots with minimum to 1,500 hours had significantly fewer Non-Completions than expected and pilots with more than 4,500 hours had significantly more Non-Completions than expected.

A chi-square test of significance compared Extra Training Events based on the 1,500 Total Flight Hours. Significant results $\left[N=5,072(75 \%), \chi^{2}(3)=26.398, p<.001\right.$, Cramer's $V=.072]$ are displayed in Table 12. Pilots with minimum to 1,500 hours required significantly fewer Extra Training Events than expected.

A chi-square test of significance compared Extra IOE based on the 1,500 Total Flight Hours. The results were not significant $\left[N=4,532(67 \%), \chi^{2}(2)=7.503, \mathrm{p}=.057\right.$, Cramer's $V=.041]$. No significant differences were found for Extra IOE based on the 1,500 Total Flight Hours.

A chi-square test of significance compared Extra Recurrent Training based on the 1,500 Total Flight Hours. Significant results $\left[N=4573(68 \%), \chi^{2}(3)=\right.$ 17.221, $p=.001$, Cramer's $V=.061]$ are displayed in Table 12. Pilots with 1,501 to 3,000 hours required significantly more Extra Recurrent Training than expected. Pilots with minimum to 1,500 hours and pilots with 4,501 to maximum hours required significantly less Extra Recurrent Training than expected.

\section{Nine Predictor Variables: Pilot Hours}

$\begin{array}{ll}\text { Synopsis-Significant Positive Results for Pilot Hours } \\ \text { Instrument Hrs } & \text { Low Instrument Hrs-Fewer } \\ & \text { Non-Completions } \\ & \text { High Instrument Hrs-Less Extra } \\ & \text { Recurrent Training } \\ & \text { Low XC Hrs-Fewer } \\ & \text { Non-Completions } \\ \text { Cross-Country Hrs } & \text { High XC Hrs-Less Extra IOE; less } \\ & \text { Extra Recurrent Training } \\ & \text { Low PIC Hrs-Fewer Non- } \\ & \text { Completions; less Extra Training }\end{array}$

Second-in-Command Hrs Low SIC Hrs-Fewer

Non-Completions; less Extra Training

High SIC Hrs-Less Extra IOE

Multiengine Hrs Low ME Hrs-Fewer Non-Completions

High ME Hrs-Less Extra IOE;

less Extra Recurrent Training

Turbine Hrs Low Turbine Hrs-Fewer Non-Completions

High Turbine Hrs-Less Extra IOE

Dual-Given Hrs Low Dual-Given Hrs-Fewer Non-Completions; less Extra Training; less Extra IOE

Total Flight Hrs Low Total Flight Hrs-Fewer Non-Completions; less Extra Training

High Total Flight Hrs-Less Extra IOE; less Extra Recurrent Training

The data collectors examined applications and résumés to extract recorded piloting experience under the headings: Total Instrument Hours, Cross-Country Hours, Pilotin-Command Hours, Second-in-Command Hours, Multiengine Hours, Turbine Hours, Dual-Given Hours, and Total Flight Hours. Neither the airlines nor the researchers validated these recorded hours. One-way between subjects ANOVAs were conducted to compare the effect of Completions/ Non-Completions on Pilot Hours. Table 13 shows that for all categories of Pilot Hours, completers had significantly fewer hours than non-completers.

One-way between subjects ANOVAs were conducted to compare the effect of Extra Training on Pilot Hours. Table 14 shows that pilots with more Pilot-in-Command Hours, more Dual-Given Hours, and more Total Flight Hours required significantly more Extra Training Events. Pilots with fewer Second-in-Command Hours required significantly more Extra Training Events.

One-way between subjects ANOVAs were conducted to compare the effect of Extra IOE on Pilot Hours. Table 15 shows that pilots with fewer Cross-Country Hours, fewer Second-in-Command Hours, fewer Multiengine Hours, fewer Turbine Hours, and less Total Flight Hours required significantly more Extra IOE. Pilots with more Dual-Given hours required significantly more Extra IOE. 
Table 13

Comparison of Pilot Hours factored by Completions.

\begin{tabular}{|c|c|c|c|c|c|c|c|c|}
\hline \multirow[b]{2}{*}{ Pilot Hours } & \multicolumn{2}{|c|}{$N$} & \multicolumn{2}{|c|}{ Mean } & \multirow[b]{2}{*}{$d f$} & \multirow[b]{2}{*}{$F$} & \multirow[b]{2}{*}{$p$} & \multirow[b]{2}{*}{$\eta^{2}$} \\
\hline & Incomplete & Complete & Incomplete & Complete & & & & \\
\hline Instrument & 702 & 3244 & 498 & 336 & 1,3944 & $19.0^{\mathrm{a}}$ & .000 & .008 \\
\hline $\mathrm{XC}$ & 719 & 3110 & 2546 & 1801 & 1,3827 & $34.0^{\mathrm{a}}$ & .000 & .012 \\
\hline PIC & 793 & 3822 & 2567 & 1666 & 1,4613 & $79.3^{\mathrm{a}}$ & .000 & .024 \\
\hline SIC & 360 & 1713 & 1638 & 1341 & 1,2071 & $8.8^{\mathrm{a}}$ & .003 & .005 \\
\hline Multiengine & 876 & 4440 & 2228 & 1527 & 1,5314 & $34.1^{\mathrm{a}}$ & .000 & .009 \\
\hline Turbine & 557 & 2633 & 2635 & 1967 & 1,3188 & $21.2^{\mathrm{a}}$ & .000 & .009 \\
\hline Dual-Given & 449 & 2859 & 1125 & 939 & 1,3306 & $15.1^{\mathrm{a}}$ & .000 & .007 \\
\hline Total Flight Hrs & 892 & 4573 & 3996 & 2894 & 1,5463 & $77.6^{\mathrm{a}}$ & .000 & .020 \\
\hline
\end{tabular}

${ }^{\text {a }}$ Since the Levene test for homogeneity of variances was significant, the Brown-Forsythe test for unequal variances was used (Laerd Statistics, 2013).

Table 14

Comparison of Pilot Hours factored by Extra Training Events.

\begin{tabular}{|c|c|c|c|c|c|c|c|c|}
\hline \multirow[b]{2}{*}{$\begin{array}{l}\text { Pilot } \\
\text { Hours }\end{array}$} & \multicolumn{2}{|c|}{$N$} & \multicolumn{2}{|c|}{ Mean } & \multirow[b]{2}{*}{$d f$} & \multirow[b]{2}{*}{$F$} & \multirow[b]{2}{*}{$p$} & \multirow[b]{2}{*}{$\eta^{2}$} \\
\hline & $\begin{array}{l}\text { No Extra } \\
\text { Training }\end{array}$ & $\begin{array}{c}\text { Yes Extra } \\
\text { Training }\end{array}$ & $\begin{array}{l}\text { No Extra } \\
\text { Training }\end{array}$ & $\begin{array}{c}\text { Yes Extra } \\
\text { Training }\end{array}$ & & & & \\
\hline Instrument & 2262 & 1322 & 347 & 360 & 1, 3582 & .3 & .592 & .000 \\
\hline $\mathrm{XC}$ & 2133 & 1363 & 1874 & 1838 & 1,3494 & .2 & .681 & .000 \\
\hline PIC & 2593 & 1648 & 1612 & 1973 & 1,4239 & $29.0^{\mathrm{a}}$ & .000 & .007 \\
\hline SIC & 1220 & 649 & 1413 & 1248 & 1,1867 & 4.6 & .033 & .002 \\
\hline Multiengine & 3037 & 1889 & 1617 & 1498 & 1,4924 & 2.4 & .125 & .000 \\
\hline Turbine & 1867 & 1031 & 2030 & 1982 & 1,2896 & .2 & .637 & .000 \\
\hline Dual-Given & 1970 & 1129 & 908 & 1025 & 1, 3097 & $18.5^{\mathrm{a}}$ & .000 & .006 \\
\hline Total Flight Hrs & 3126 & 1946 & 2896 & 3103 & 1,5070 & $6.3^{\mathrm{a}}$ & .012 & .001 \\
\hline
\end{tabular}

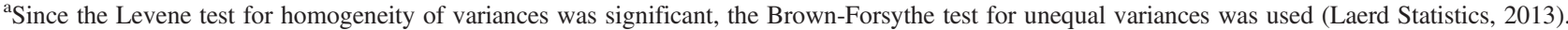

Table 15

Comparison of Pilot Hours factored by Extra IOE.

\begin{tabular}{|c|c|c|c|c|c|c|c|c|}
\hline \multirow[b]{2}{*}{ Pilot Hours } & \multicolumn{2}{|c|}{$N$} & \multicolumn{2}{|c|}{ Mean } & \multirow[b]{2}{*}{$d f$} & \multirow[b]{2}{*}{$F$} & \multirow[b]{2}{*}{$p$} & \multirow[b]{2}{*}{$\eta^{2}$} \\
\hline & No Extra IOE & Yes Extra IOE & No Extra IOE & Yes Extra IOE & & & & \\
\hline Instrument & 2829 & 384 & 341 & 295 & 1,3211 & 1.9 & .174 & .001 \\
\hline $\mathrm{XC}$ & 2703 & 386 & 1858 & 1346 & 1,3087 & $22.2^{\mathrm{a}}$ & .000 & .005 \\
\hline PIC & 3322 & 470 & 1656 & 1681 & 1,3790 & .1 & .797 & .000 \\
\hline SIC & 1551 & 149 & 1370 & 1007 & 1,1698 & 7.5 & .006 & .004 \\
\hline Multi & 3855 & 544 & 1584 & 1079 & 1,4397 & $28.5^{\mathrm{a}}$ & .000 & .004 \\
\hline Turbine & 2349 & 262 & 2005 & 1526 & 1,2609 & 8.4 & .004 & .003 \\
\hline Dual-Given & 2499 & 341 & 917 & 1104 & 1,2838 & $17.7^{\mathrm{a}}$ & .000 & .008 \\
\hline Total Flight Hrs & 3972 & 560 & 2914 & 2696 & 1,4530 & $3.8^{\mathrm{a}}$ & .050 & .001 \\
\hline
\end{tabular}

${ }^{a}$ Since the Levene test for homogeneity of variances was significant, the Brown-Forsythe test for unequal variances was used (Laerd Statistics, 2013).

One-way between subjects ANOVAs were conducted to compare the effect of Extra Recurrent Training on Pilot Hours. Table 16 shows that pilots with fewer Instrument Hours, fewer Cross-Country Hours, fewer Multiengine Hours, and fewer Total Flight Hours required significantly more Extra Recurrent Training.

\section{Multivariate Analysis}

Appendix A summarizes the univariate analysis. In order to understand the interactions among the background variables, a Chi-Square Automatic Interaction Detection (CHAID) predictive analytic technique was used to evaluate the complex interactions among the background variables on the outcome variables. SPSS release 23.0 was used for the analyses. CHAID decision trees select the background independent variables that have the strongest relationship with the outcome dependent variables. The dependent variables in these analyses were either Completions or Extra Training Events. Appendix B summarizes the Multivariate analysis.

Two different sets of background variables were used with each of the outcome variables: Educational Background 
Table 16

Comparison of Pilot Hours factored by Extra Recurrent Training.

\begin{tabular}{|c|c|c|c|c|c|c|c|c|}
\hline \multirow[b]{2}{*}{$\begin{array}{l}\text { Pilot } \\
\text { Hours }\end{array}$} & \multicolumn{2}{|c|}{$N$} & \multicolumn{2}{|c|}{ Mean } & \multirow[b]{2}{*}{$d f$} & \multirow[b]{2}{*}{$F$} & \multirow[b]{2}{*}{$p$} & \multirow[b]{2}{*}{$\eta^{2}$} \\
\hline & $\begin{array}{l}\text { No Extra } \\
\text { Recurrent }\end{array}$ & $\begin{array}{l}\text { Yes Extra } \\
\text { Recurrent }\end{array}$ & $\begin{array}{l}\text { No Extra } \\
\text { Recurrent }\end{array}$ & $\begin{array}{l}\text { Yes Extra } \\
\text { Recurrent }\end{array}$ & & & & \\
\hline Instrument & 4538 & 259 & 363 & 263 & 1,4795 & $19.2^{\mathrm{a}}$ & .000 & .001 \\
\hline $\mathrm{XC}$ & 4528 & 216 & 1933 & 1520 & 1,4742 & $7.8^{\mathrm{a}}$ & .006 & .001 \\
\hline PIC & 5329 & 307 & 1836 & 1917 & 1,5634 & $.6^{\mathbf{a}}$ & .429 & .000 \\
\hline SIC & 2409 & 117 & 1407 & 1154 & 1,2524 & 2.7 & .098 & .001 \\
\hline Multi & 6054 & 363 & 1664 & 1232 & 1,6415 & $12.8^{\mathrm{a}}$ & .000 & .001 \\
\hline Turbine & 3659 & 175 & 2101 & 1802 & 1,3832 & 2.0 & .156 & .001 \\
\hline Dual-Given & 3691 & 243 & 934 & 1027 & 1, 3932 & 3.6 & .058 & .001 \\
\hline Total Flight Hrs & 6296 & 366 & 3092 & 2715 & 1,6660 & $9.4^{\mathrm{a}}$ & .002 & .001 \\
\hline
\end{tabular}

${ }^{\text {a}}$ Since the Levene test for homogeneity of variances was significant, the Brown-Forsythe test for unequal variances was used (Laerd Statistics, 2013).

and Experience Background. Table 17 shows the variables that were included in these analyses.

Table 17

Background variables included in Educational Background and Experience Background.

\begin{tabular}{ll}
\hline \multicolumn{1}{c}{ Educational Background } & \multicolumn{1}{c}{ Experience Background } \\
\hline Aviation Degree $^{\mathrm{a}}$ & ATP Certificate \\
- AABI-Accredited Flight & - IA R-ATP \\
- Not AABI-Accredited Flight & - M R-ATP \\
- Non-Aviation Degree & - Traditional ATP \\
- No College Degree & Flight Instructor \\
Years Since Graduation & Previous Employment \\
Total Flight Hrs & Total Flight Hrs \\
Flight Instructor & \\
\hline
\end{tabular}

${ }^{\mathrm{a}}$ Forced as the first variable into the analysis.

\section{Completions and the Educational Background Characteristics}

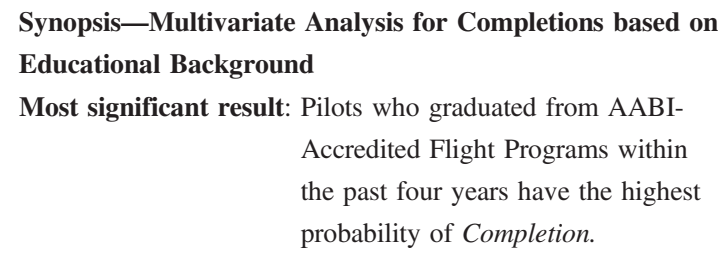

Figure 4 shows the analysis of Completions and the Educational Background characteristics; 5,487 cases were included in the analysis. The CHAID analysis was significant, using Aviation Degree as the first branch on the tree: $N=5,487(81 \%), \chi^{2}(3)=78.535, p<.001$, risk estimate $=.163, S E=.005$. The model correctly predicted $84 \%$ of the overall cases and $100 \%$ of the cases that had Completions. For the second branch, Years Since Graduation was significant for AABI-Accredited Flight $\left[N=1,277(19 \%), \chi^{2}(2)=73.379, p<.001\right]$, Not AABIAccredited Flight $\left[N=1,415(21 \%), \chi^{2}(2)=87.203\right.$, $p<.001]$, and Non-Aviation Degree $[N=1,800$ (27\%), $\left.\chi^{2}(2)=67.130, p<.001\right]$. For No College Degree, Total Flight Hours was significant $\left[N=995(15 \%), \chi^{2}(1)=\right.$ 20.896, $p<.001]$. For the third branch, Instructor was significant for No College Degree with LE 3,000 Total Flight Hours $\left[N=634\right.$ (9\%), $\left.\chi^{2}(1)=6.630, p=.03\right]$. The tree diagram is presented in Figure 4.

The tree diagram is read from top to bottom and left to right. The probabilities are multiplicative. Using the first branch of Figure 4 ("Completions based on Educational Background") as an example, if pilots graduated from AABIAccredited Flight Programs, there is a [84\% x 91\% =] 76\% probability of completing training, compared to [84\% $\mathrm{x}$ $85 \%=$ ] $71 \%$ for graduates with an Aviation Degree (not including AABI-Accredited Flight), [84\% x 81\% =] 68\% for graduates with a Non-Aviation Degree, and [84\% x $78 \%=$ ] $66 \%$ for pilots with No College Degree. Further, using the second branch of Figure 4, if pilots graduated from an AABI-Accredited Flight Program within the past four years, there is a $[84 \% \times 91 \%$ x $97 \%=] 74 \%$ probability of Completion, compared to $[84 \%$ x $91 \%$ x $91 \%=] 70 \%$ for pilots who graduated from an AABIAccredited Flight Program between four and ten years ago and $[84 \% \times 91 \% \times 73 \%=] 56 \%$ for pilots who graduated from an AABI-Accredited Flight Program more than ten years ago. Figure 4 shows the probabilities of Completion for the last branch of the multivariate analysis. Pilots who graduated from an AABI-Accredited Flight Program fewer than four years ago had the highest probability (74\%) of Completion.

\section{Extra Training Events and the Educational Background Characteristics}

Synopsis-Multivariate Analysis for Extra Training Based on Educational Background

Most significant result: Pilots who graduated from AABI-Accredited Flight Programs within the past nine years have the highest probability of No Extra Training. 


\section{COMPLETIONS based on Educational Background $84 \%(N=5,487)$}

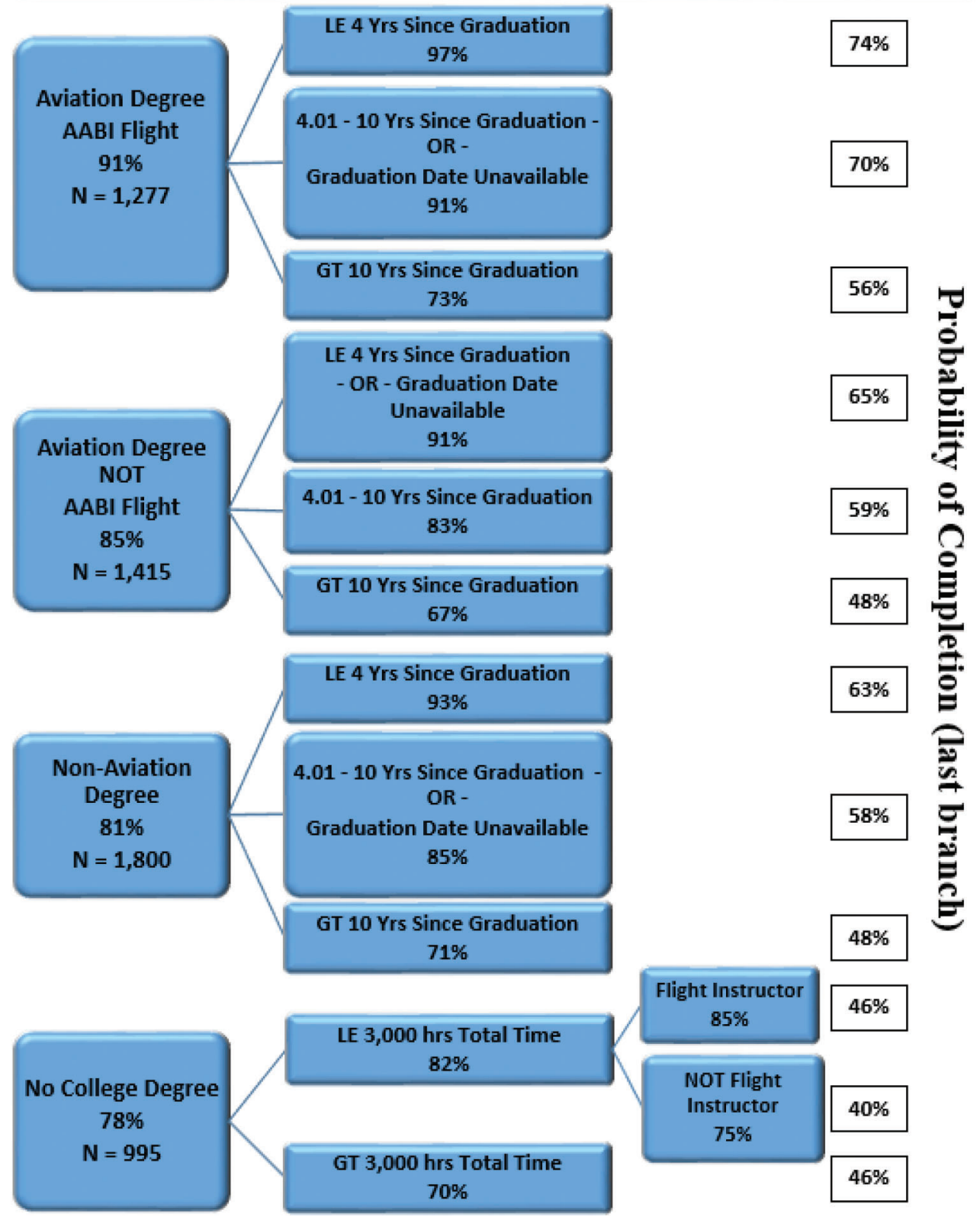

Figure 4. Tree diagram of Completions based on Educational Background variables.

Figure 5 shows the analysis of Extra Training Events and the related educational background characteristics; 5,091 cases were included in this analysis. The CHAID analysis was significant using Aviation Degree as the first branch on the tree: $N=5,091(76 \%), \chi^{2}(2)=86.449$, $p<.001$, risk estimate $=.381, S E=.007$. The model correctly predicted $62 \%$ of the overall cases and $99.1 \%$ of the cases that had No Extra Training Events. For the second branch, Years Since Graduation was significant for AABIAccredited Flight $\left[N=1,230(18 \%), \chi^{2}(1)=18.703\right.$, $p<.001]$, Not AABI-Accredited Flight $[N=1,323$ (20\%), $\left.\chi^{2}(2)=18.081, p=.001\right]$, and Non-Aviation Degree $N=2,538$ (38\%), $\left.\chi^{2}(1)=10.406, p=.006\right]$. There were no significant variables for the third branch. The tree diagram is presented in Figure 5.

Using the first branch of Figure 5 ("No Extra Training Events based on Educational Background") as an example, if pilots graduated from AABI-Accredited Flight Programs, there is a $[62 \% \times 72 \%=] 45 \%$ probability of No Extra Training Events, compared to [62\% x 62\% =] 38\% for pilots 


\section{NO Extra Training Events based on Educational Background} $62 \%(\mathrm{~N}=5,091)$

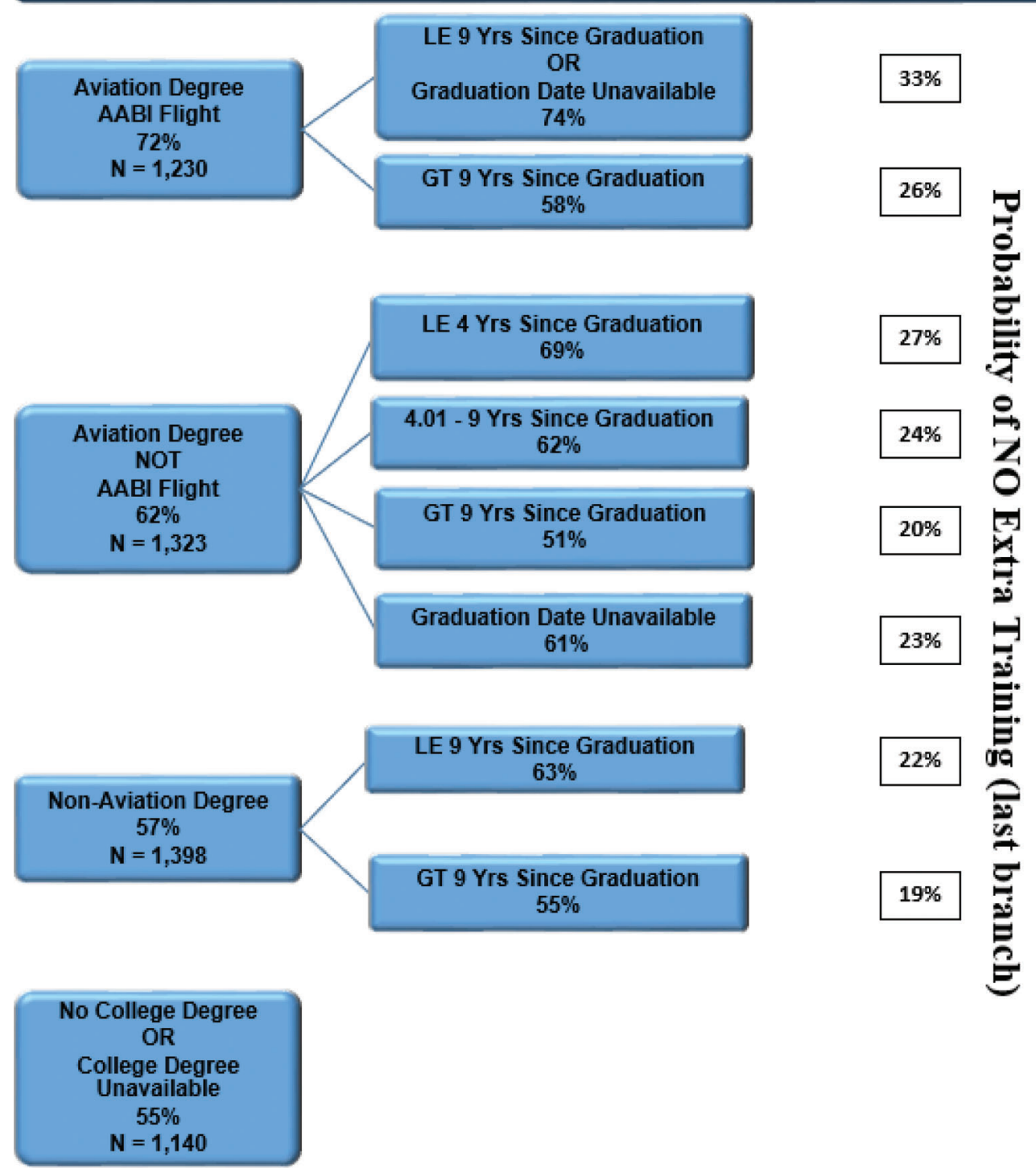

Figure 5. Tree diagram of Extra Training Events based on Educational Background variables.

with an Aviation Degree (Not AABI-Accredited Flight), $[62 \% \times 57 \%=] 35 \%$ for pilots with a Non-Aviation Degree, and $[62 \% \times 55 \%=] 34 \%$ for pilots with No College Degree. Further, if pilots graduated from an AABIAccredited Flight Program fewer than nine years ago, there is a $[62 \% \times 72 \% \times 74 \%=] 33 \%$ probability of No Extra Training Events, compared to [62\% x $72 \%$ x $58 \%=] 26 \%$ probability of No Extra Training Events for pilots who graduated from an AABI-Accredited Flight Program more than nine years ago. Figure 5 shows the probabilities of $\mathrm{No}$ Extra Training Events for the last branch of the multivariate analysis. Pilots who graduated from an AABI-Accredited Flight Program fewer than nine years ago had the highest probability (33\%) of No Extra Training Events.
Completions and the Experience Background Characteristics

Synopsis-Multivariate Analysis for Completions Based on Experience

Most significant results: Pilots with IA R-ATP Certificates had a higher probability of Completion than pilots with M R-ATP Certificates and Traditional ATP Certificates.

Among pilots with Traditional ATP Certificates, pilots with minimum Total Flight Hours (1,500 hours) and a CFI Certificate had the highest probability of Completion. 


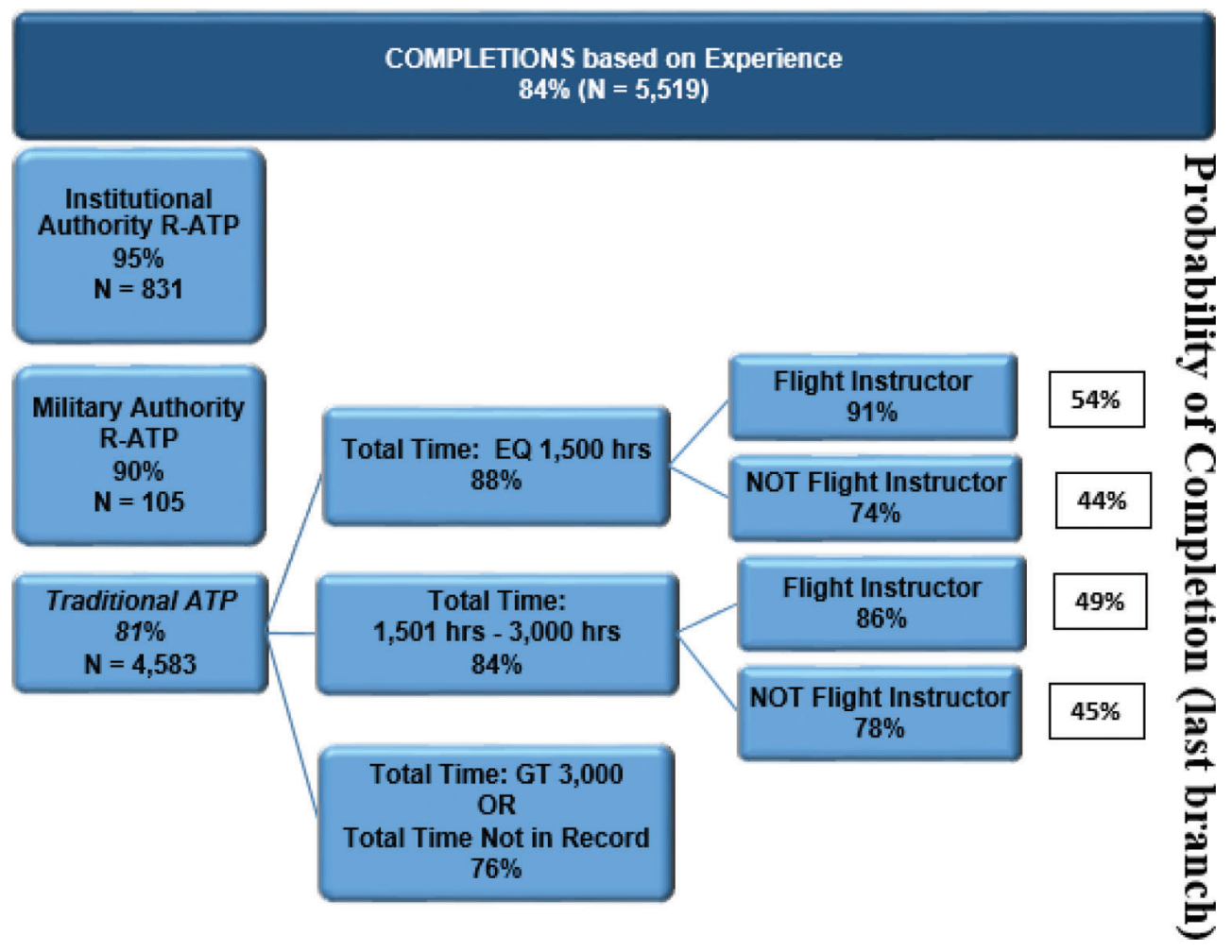

Figure 6. Tree diagram of Completions based on Experience Background characteristics.

Figure 6 shows the analysis of Completions and the Experience Background characteristics; 5,519 (82\%) cases were included in the analysis. The CHAID analysis was significant using "ATP Certificate" as the first branch on the tree: $N=5,519(82 \%), \chi^{2}(2)=105.064, p<.001$, risk estimate $=.164, S E=.005$. The model correctly predicted $84 \%$ of the overall cases and $100 \%$ of the cases that had Completions. For the second branch, Total Flight Hours was significant for Traditional ATP $[N=4,583(68 \%)$, $\left.\chi^{2}(2)=60.460, p<.001\right]$. For the third branch, Flight Instructor was significant for Total Flight Hours $\leq 1,500$ hours $\left[N=500(7 \%), \chi^{2}(1)=17.011, p<.000\right]$ and for Total Flight Hours between 1,501-3,000 hours $[N=2,302$ (34\%), $\left.\chi^{2}(1)=19.705, p<.001\right]$. The tree diagram is presented in Figure 6.

Using the first branch of Figure 6 ("Completions based on Experience") as an example, if pilots have IA R-ATP certificates, there is an $[84 \% \times 95 \%=] 80 \%$ probability of Completion, compared to $[84 \% \times 90 \%=] 76 \%$ probability of Completion for M R-ATP Certificates, and [84\% x $81 \%=] 68 \%$ probability of Completion for traditional ATP Certificates. Further, using the second branch of Figure 6, if traditional ATP pilots have the minimum required Total Flight Hours (1,500 hours), there is a $[84 \%$ x $81 \%$ x $88 \%=$ ] $60 \%$ probability of Completion, compared to [84\% x $81 \% \times 84 \%=] 57 \%$ for pilots with intermediate Total Flight Hours (between 1,501 and 3,000 hours) and $[84 \% \times 81 \% \times 76 \%=] 52 \%$ for pilots with high Total Flight Hours (more than 3,000 hours). Figure 6 shows the probabilities of Completion for the last branch of the multivariate analysis. Pilots who had the minimum Total Flight Hours (1,500 hours) and a CFI Certificate had the highest probability of Completion (54\%) for pilots with a Traditional ATP Certificate.

\section{Extra Training Events and the Experience Background Characteristics}

Synopsis-Multivariate Analysis for Extra Training Based on
Experience
$\begin{aligned} & \text { Most significant results: Pilots with IA R-ATP Certificates and } \\ & \text { M R-ATP Certificates had a higher } \\ & \text { probability of No Extra Training than } \\ & \text { pilots with Traditional ATP Certificates. } \\ & \text { Among pilots with Traditional ATP } \\ & \text { Certificates, pilots with prior Part } 121 \text { or } \\ & \text { military flight experience had the highest } \\ & \text { probability of No Extra Training. }\end{aligned}$

Figure 7 shows the analysis of Extra Training Events and the Experience Background characteristics; 5,118 (76\%) cases were included in the analysis. The CHAID analysis was significant using "ATP Certificate" as the first branch on the tree: $N=5,118(76 \%), \chi^{2}(1)=38.213$, $p<.001$, risk estimate $=.375, S E=.007$. The model correctly predicted $62 \%$ of the cases and $91.3 \%$ of the cases that had No Extra Training Events. For the second branch, the independent variable Previous Employment was significant 


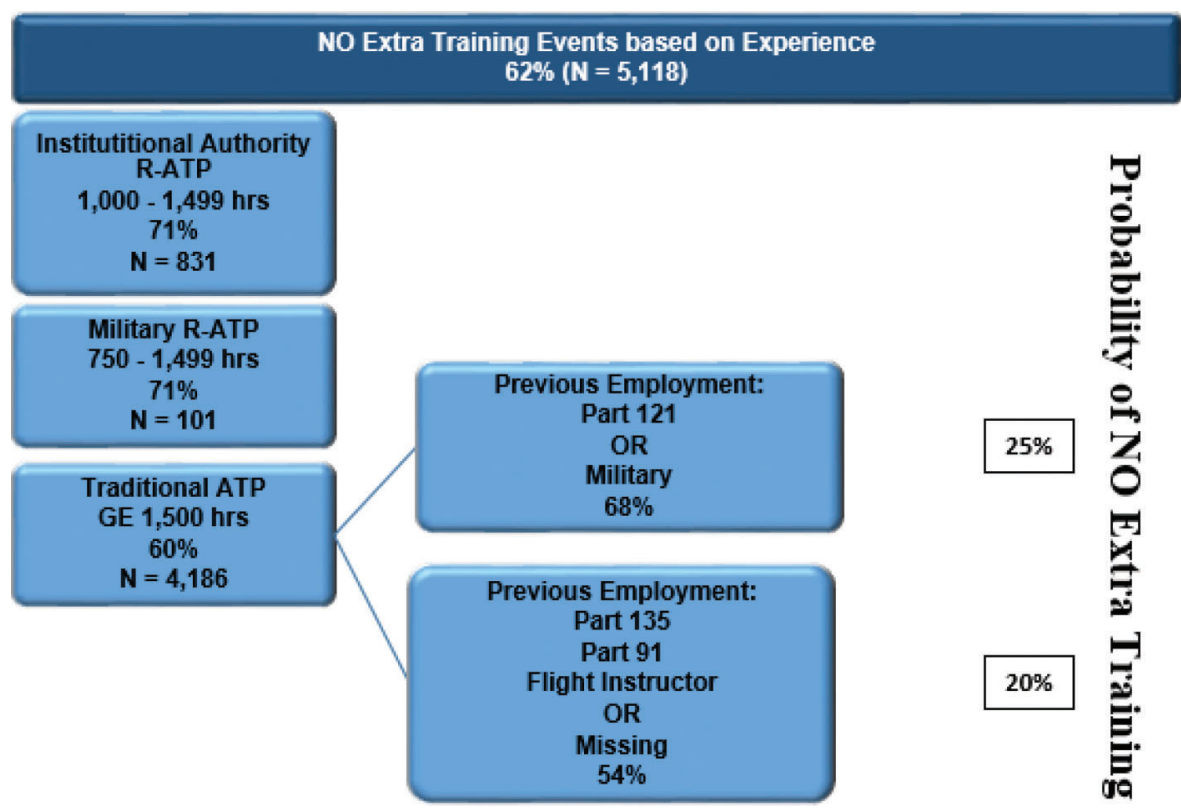

Figure 7. Tree diagram of Extra Training Events based on Experience Background characteristics.

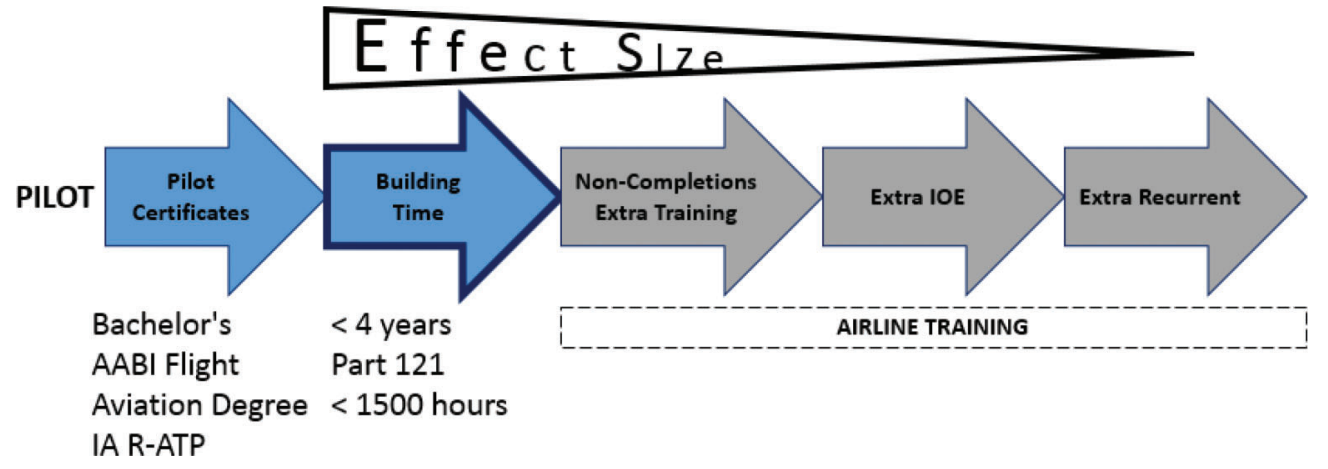

Figure 8. Timeline of pilot development with significant background variables.

for Traditional ATP $\left[N=4,189(62 \%), \chi^{2}(1)=81.485\right.$, $p<.001]$. There were no significant variables for the third branch. The tree diagram is presented in Figure 7.

Using the first branch of Figure 7 ("No Extra Training Events based on Experience") as an example, if pilots have IA R-ATP Certificates, there is a $[62 \% \times 71 \%=] 44 \%$ probability of No Extra Training Events, compared to [62\% x $71 \%=] 44 \%$ for M R-ATP Certificates and [62\% x $60 \%=$ ] $37 \%$ for traditional ATP Certificates. Further, using the second branch of Figure 7, if Traditional ATP pilots were previously Part 121 or military pilots, there is a $[62 \% \times 60 \% \times 68 \%=] 25 \%$ probability of No Extra Training Events, compared to $[62 \%$ x $60 \%$ x $54 \%=] 20 \%$ for pilots from a Part 135, Part 91, or Flight Instructor background. Figure 7 shows the probabilities of No Extra Training Events for the last branch of the multivariate analysis. Pilots with prior Part 121 or military flight experience had the highest probability of No Extra Training Events (25\%) for pilots with a Traditional ATP Certificate.

\section{Discussion}

Public Law 111-216 is entitled the "Airline Safety and Federal Aviation Administration Extension Act of 2010" because the stated goal of the public law is to improve safety. It is important to understand that neither this study, which includes the previous report on pilot background characteristics (Bjerke et al., 2016), nor either of the two previous Pilot Source Studies (Smith et al., 2010; Smith et al., 2013) collected data on "safety." Airline safety data, especially regarding airline accidents, is rare and difficult to collect. The Pilot Source Studies collected outcome data on pilot performance with the assumption that pilot performance is related to safety. Several studies (Dismukes, 2009; Sexton \& Klinect, 2001; Wickens et al., 2009) have linked pilot performance to safety, at least to safety culture. Specifically, Sexton and Klinect (2001) found that crews composed of pilots with positive perceptions of safety culture had better overall crew performance ratings than crews with negative perceptions of safety culture. 
Table 18

Background variables sorted by effect size.

\begin{tabular}{llll}
\hline \multicolumn{1}{c}{ Effect Size-Non-Completions/Extra Training } & & \multicolumn{1}{c}{ Effect Size-IOE/Recurrent } \\
\hline Years Since Graduation $-\leq 4$ Yrs. & .208 & Previous Employment - Part 121 \\
Total Flight Hours-1500 Hour $-\leq 1500 \mathrm{Hrs}$ & .122 & Years Since Graduation $-\leq 4$ Yrs. \\
AABI-Accredited Flight - Yes & .115 & Total Flight Hours-1500 Hour $-\leq 1500$ Hrs \\
ATP Certificate - IA R-ATP & .113 & Aviation Degree - Yes \\
Aviation Degree - Yes & .103 & AABI-Accredited Flight - Yes \\
Highest Degree - Bachelor's & .101 & ATP Certificate - IA R-ATP \\
Previous Employment - Part 121 & .088 & & .060 \\
Military Pilot - Yes & .032 & & \\
\hline
\end{tabular}

Figure 8 describes a timeline summary of the performance variables in this study (gray arrows) and the background variables (blue arrows) that demonstrated significant success in regional airline training. Figure 8 also demonstrates the concept of effect size. A pilot's initial training (certificates) and "building time" experiences should have a stronger effect on Non-Completions and Training than on Extra IOE or Extra Recurrent Training. The "building time" gap between pilot certificates and regional airline training has always existed, but the extent of "building time" was a choice made by the hiring airline. Public Law 111-216 and the FOQ Rule significantly extended the "building time" gap, thereby reducing the effect of the significant training variables on a pilot's success in airline training.

Though effect sizes were relatively small in this study, a real effect of the significant background variables influences the outcome variables. Table 18 shows the significant background variables, sorted by effect size.

Because of effect size, the most relevant outcome variables in the study were those shown in Table 18 under Non-Completions and Extra Training. In order to understand the interactions among the background variables, a Chi-Square Automatic Interaction Detection (CHAID) predictive analytic technique was used to evaluate the complex interactions among the background variables on the outcome variables.

\section{Conclusions}

Appendix A presents a summary of the quantitative results of the Pilot Source Study 2015. There are four outcome variables: Non-Completions, Extra Training, Extra IOE, and Extra Recurrent Training. A pilot's background has a stronger effect on Non-Completions and Extra Training; they are the most immediate outcomes when a pilot is hired by a regional airline and begins training. A pilot's background has less effect on Extra IOE because the airline's training program provides an intermediary link between pilots' backgrounds and their performance in IOE. Moreover, for Extra Recurrent Training, airline training and operational flying have more effect than past background variables.
The first outcome variable to consider is NonCompletions. Though the dataset does not include a "reason code" for Non-Completions (or terminations), it is reasonable to assume that many of the 906 NonCompletions were performance related. Excluding pilots who were still in training, these non-completers constitute $16 \%$ of the pilots in the study population. This percentage is supported by an airline training manager who estimated that $15-18 \%$ of their new-hire pilots were terminated due to failure to progress. Considering Educational Backgrounds, more Completions were attributed to pilots with a bachelor's degree, pilots who graduated from AABI-Accredited Flight Programs, and pilots who had an Aviation-Related Degree. Considering previous experience, more Completions were attributed to pilots who graduated from college fewer than four years ago, and pilots with lower Total Flight Hours. Considering pilot certificates, more Completions were attributed to pilots with an IA R-ATP and pilots with $\leq 1,500$ hours of total flight time. Considering piloting hours, more Completions were attributed to pilots who had fewer hours in the categories of Instrument Hours, Cross-Country Hours, Pilot-in-Command Hours, Second-in-Command Hours, Multiengine Hours, Turbine Hours, Dual-Given Hours, and Total Flight Hours. These considerations suggest that pilots who recently graduated (within the past four years) with bachelor's degrees from aviation programs-preferably from AABI-accredited flight programs - and attained additional flight hours as flight instructors were more likely to successfully complete an airline training program, even though they probably had fewer of the piloting hours often considered to be a formula for success in airline piloting (e.g., Multiengine and Turbine Hours).

The second outcome variable to consider is Extra Training. As previously stated, Extra Training is greatly understated in the dataset because many extra training sessions were not recorded or training departments did not retain detailed training records after pilots completed their training. One training manager stated that passing the required training on the first attempt is the ideal; however, it is becoming more common for new-hire pilots to need some additional training to be successful. Another training manager estimated that $75-80 \%$ of current new-hire pilots 
required additional training; whereas in the past few years it was unlikely that someone required additional training. Considering Educational Backgrounds, less Extra Training was attributed to pilots with a bachelor's degree, particularly pilots who graduated from AABI-Accredited Flight Programs. Recent college graduates (within the last four years) who had an Aviation-Related Degree required less Extra Training. Considering previous experience, less Extra Training was attributed to pilots who held the IA R-ATP Certificate and graduated from college fewer than four years ago. Among traditional ATPs, pilots who were prior military or whose Previous Employment was Part 121 required less Extra Training. Considering piloting hours, less Extra Training was attributed to pilots who had fewer hours in the categories of Pilot-in-Command Hours, Second-in-Command Hours, Dual-Given Hours, and Total Flight Hours. Overall, the data suggest that pilots who needed less Extra Training were recent college graduates (within the last four years) who pursued an aviation education, pilots with an IA R-ATP and $\leq 1,500$ hours of total flight time, prior-military pilots, and pilots with previous Part 121 experience.

The third outcome variable to consider is Extra IOE. Almost every airline stated that it was customary to extend IOE hours for operational or scheduling reasons, not related to performance; however, excessive IOE was most likely performance related. This study used a very conservative definition for Extra IOE - only those pilots whose IOE hours were more than one standard deviation (+1 SD) above the airline's average IOE hours were labeled as needing Extra IOE. Considering educational backgrounds, less Extra IOE was attributed to pilots who graduated from AABI-Accredited Flight programs. Considering previous experience, less Extra IOE was attributed to pilots whose previous employment was Part 121 . There were no pilot certificate variables that produced less Extra IOE. Considering piloting hours, less Extra IOE was attributed to pilots who had more hours in the categories of CrossCountry Hours, Second-in-Command Hours, Multiengine Hours, Turbine Hours, and Total Flight Hours. One result that is difficult to explain is that less Extra IOE was attributed to pilots with fewer hours of Dual-Given. Pilots who graduated from AABI-Accredited Flight Programs extended their educational advantage to IOE, requiring less Extra IOE. Whereas limited piloting experience (piloting hours) did not increase Non-Completions or Extra Training, more piloting experience, especially in Part 121 operations, decreased Extra IOE, perhaps because IOE is accomplished in an aircraft instead of a classroom or flight simulator.

The fourth outcome variable to consider is Extra Recurrent Training. As stated earlier, there are many intervening airline variables that are more likely to impact Extra Recurrent Training than pilot background variables.
However, several background variables did show a significant influence on Extra Recurrent Training. Considering Educational Backgrounds, less Extra Recurrent Training was attributed to pilots who graduated from AABIAccredited Flight Programs, and pilots who had an Aviation-Related Degree. Considering previous experience, less Extra Recurrent Training was attributed to pilots who graduated from college fewer than four years ago and pilots whose previous employment was Part 121. Considering pilot certificates, less Extra Recurrent Training was attributed to pilots with an IA R-ATP. Also, pilots with minimum to 1,500 hours of total flight time and pilots with more than 4,500 hours of total flight time required less Extra Recurrent Training. Considering piloting hours, less Extra Recurrent Training was attributed to pilots who had more hours in the categories of Instrument Hours, CrossCountry Hours, Multiengine Hours, and Total Flight Hours.

Appendix B is a summary of the multivariate CHAID analysis that evaluated the interactions among the background variables on the outcome variables. The significant background variables were clustered into Educational Backgrounds and Experience Backgrounds. The significant outcome variables were Completions and Extra Training. The most significant result for Completions based on Educational Background was that pilots who graduated from AABI-Accredited Flight Programs within the past four years have the highest probability of Completion. The most significant result for Extra Training based on Educational Background was that pilots who graduated from AABI-Accredited Flight Programs within the past nine years have the highest probability of No Extra Training. The two most significant results for Completions based on Experience were (a) pilots with IA R-ATP Certificates had a higher probability of Completion than pilots with $\mathrm{M}$ R-ATP Certificates and Traditional ATP Certificates; and (b) among pilots with Traditional ATP Certificates, pilots with minimum Total Flight Hours (1,500 hours) and a CFI Certificate had the highest probability of Completion. The two most significant results for Extra Training based on Experience were (a) pilots with IA R-ATP Certificates and M R-ATP Certificates had a higher probability of No Extra Training than pilots with Traditional ATP Certificates; and (b) among pilots with Traditional ATP Certificates, pilots with prior Part 121 or military flight experience had the highest probability of No Extra Training.

Pilots who graduated from AABI-Accredited Flight Programs had the most consistent results. Of all the background variables, only graduating from AABI-Accredited Flight Programs had a positive effect on all four of the outcome variables. Our research suggests that, contrary to airline historical logic and hiring practices; new hires who are younger, less experienced, and recently degreed ( $<4$ years) from an AABI-accredited aviation program are preferable to all other candidate hiring options. 


\section{Appendix A Summary of Univariate Analysis}

\begin{tabular}{|c|c|c|c|c|}
\hline Highest Degree & Non-Completions & Extra Training & Extra IOE & Extra Recurrent \\
\hline $\begin{array}{l}\text { Positive Outcome } \\
\text { Negative Outcome }\end{array}$ & $\begin{array}{l}\text { Bachelor's - FEWER } \\
\text { High School - MORE } \\
\text { Associate - MORE }\end{array}$ & $\begin{array}{l}\text { Bachelor's - LESS } \\
\text { High School - MORE } \\
\text { Associate - MORE }\end{array}$ & $\begin{array}{c}- \\
\text { Associate - MORE } \\
-\end{array}$ & $\begin{array}{l}- \\
- \\
-\end{array}$ \\
\hline AABI Flight & Non-Completions & Extra Training & Extra IOE & Extra Recurrent \\
\hline $\begin{array}{l}\text { Positive Outcome } \\
\text { Negative Outcome }\end{array}$ & $\begin{array}{c}\text { AABI-FEWER } \\
-\end{array}$ & $\begin{array}{c}\text { AABI-LESS } \\
-\end{array}$ & $\begin{array}{c}\text { AABI-LESS } \\
-\end{array}$ & $\begin{array}{c}\text { AABI-LESS } \\
-\end{array}$ \\
\hline Aviation Degree & Non-Completions & Extra Training & Extra IOE & Extra Recurrent \\
\hline $\begin{array}{l}\text { Positive Outcome } \\
\text { Negative Outcome }\end{array}$ & $\begin{array}{c}\text { Aviation -FEWER } \\
\text { Non-Aviation - MORE }\end{array}$ & $\begin{array}{c}\text { Aviation -LESS } \\
\text { Non-Aviation - MORE }\end{array}$ & Non-Aviation - MORE & $\begin{array}{c}\text { Aviation -LESS } \\
\text { Non-Aviation - MORE }\end{array}$ \\
\hline College GPA & Non-Completions & Extra Training & Extra IOE & Extra Recurrent \\
\hline $\begin{array}{l}\text { Positive Outcome } \\
\text { Negative Outcome }\end{array}$ & - & $<3.0-\mathrm{MORE}$ & $<3.0-$ MORE & $<3.0-\stackrel{-}{-}$ MORE \\
\hline Years Since Grad & Non-Completions & Extra Training & Extra IOE & Extra Recurrent \\
\hline $\begin{array}{l}\text { Positive Outcome } \\
\text { Negative Outcome }\end{array}$ & $\begin{array}{l}\leq 4 \text { Yrs. }- \text { FEWER } \\
>10 \text { Yrs. }- \text { MORE }\end{array}$ & $\begin{array}{l}\leq 4 \text { Yrs. }- \text { LESS } \\
>10 \text { Yrs. }- \text { MORE }\end{array}$ & $>10$ Yrs. - MORE & $\begin{array}{c}\leq 4 \text { Yrs. }- \text { LESS } \\
>10 \text { Yrs. }- \text { MORE }\end{array}$ \\
\hline Pre-Employment & Non-Completions & Extra Training & Extra IOE & Extra Recurrent \\
\hline $\begin{array}{l}\text { Positive Outcome } \\
\text { Negative Outcome }\end{array}$ & $\begin{array}{l}\text { Flt Instr. - FEWER } \\
\text { Part } 91 \text { - MORE }\end{array}$ & $\begin{array}{l}\text { Part } 121-\text { LESS } \\
\text { Part } 91-\text { MORE }\end{array}$ & $\begin{array}{l}\text { Part } 121 \text { - LESS } \\
\text { Flt Instr. - MORE }\end{array}$ & $\begin{array}{l}\text { Part } 121 \text { - LESS } \\
\text { Flt Instr. - MORE }\end{array}$ \\
\hline CFI Certificate & Non-Completions & Extra Training & Extra IOE & Extra Recurrent \\
\hline $\begin{array}{l}\text { Positive Outcome } \\
\text { Negative Outcome }\end{array}$ & $\begin{array}{c}- \\
\text { Non-CFI - MORE }\end{array}$ & Non-CFI - MORE & $\begin{array}{l}- \\
-\end{array}$ & - \\
\hline Military Pilot & Non-Completions & Extra Training & Extra IOE & Extra Recurrent \\
\hline $\begin{array}{l}\text { Positive Outcome } \\
\text { Negative Outcome }\end{array}$ & $\begin{array}{l}- \\
-\end{array}$ & $\begin{array}{c}\text { Military Pilot - LESS } \\
-\end{array}$ & $\begin{array}{l}- \\
-\end{array}$ & $\begin{array}{l}- \\
-\end{array}$ \\
\hline ATP Certificate & Non-Completions & Extra Training & Extra IOE & Extra Recurrent \\
\hline $\begin{array}{l}\text { Positive Outcome } \\
\text { Negative Outcome }\end{array}$ & $\begin{array}{c}\text { IA R-ATP - FEWER } \\
- \\
\end{array}$ & $\begin{array}{c}\text { IA R-ATP - LESS } \\
- \\
\end{array}$ & - & $\begin{array}{c}\text { IA R-ATP - LESS } \\
- \\
\end{array}$ \\
\hline Total Flight Hrs-1500 HR & Non-Completions & Extra Training & Extra IOE & Extra Recurrent \\
\hline $\begin{array}{l}\text { Positive Outcome } \\
\text { Negative Outcome }\end{array}$ & $\begin{array}{c}\leq 1500 \mathrm{HR}-\text { FEWER } \\
- \\
>4500 \mathrm{HR}-\mathrm{MORE}\end{array}$ & $\begin{array}{c}\leq 1500 \text { HR }- \text { LESS } \\
- \\
-\end{array}$ & $\begin{array}{l}- \\
- \\
-\end{array}$ & $\begin{array}{c}\leq 1500 \mathrm{HR}-\text { LESS } \\
>4500 \mathrm{HR}-\text { LESS } \\
1501-3000 \mathrm{HR}-\mathrm{MORE}\end{array}$ \\
\hline Instrument Hours & Non-Completions & Extra Training & Extra IOE & Extra Recurrent \\
\hline Positive Outcome & Low Inst. - FEWER & - & - & High Inst. - LESS \\
\hline XC Hours & Non-Completions & Extra Training & Extra IOE & Extra Recurrent \\
\hline Positive Outcome & Low XC - FEWER & - & High XC - LESS & High XC - LESS \\
\hline PIC Hours & Non-Completions & Extra Training & Extra IOE & Extra Recurrent \\
\hline Positive Outcome & Low PIC - FEWER & Low PIC - LESS & - & - \\
\hline SIC Hours & Non-Completions & Extra Training & Extra IOE & Extra Recurrent \\
\hline Positive Outcome & Low SIC - FEWER & Low SIC - LESS & High SIC - LESS & - \\
\hline ME Hours & Non-Completions & Extra Training & Extra IOE & Extra Recurrent \\
\hline Positive Outcome & Low ME - FEWER & - & High ME - LESS & High ME - LESS \\
\hline Turbine Hours & Non-Completions & Extra Training & Extra IOE & Extra Recurrent \\
\hline Positive Outcome & Low Turbine - FEWER & - & High Turbine - LESS & - \\
\hline Dual-Given Hours & Non-Completions & Extra Training & Extra IOE & Extra Recurrent \\
\hline Positive Outcome & Low Dual - FEWER & Low Dual - LESS & Low Dual - LESS & - \\
\hline Total Flight Hrs-Mean & Non-Completions & Extra Training & Extra IOE & Extra Recurrent \\
\hline Positive Outcome & Low TT - FEWER & Low TT - LESS & High TT - LESS & High TT - LESS \\
\hline
\end{tabular}




\section{Appendix B Summary of Multivariate Analysis}

\section{Completions Based on Educational Background}

Pilots who graduated from AABI-Accredited Flight Programs within the past four years have the highest probability of Completion.

Extra Training Based on Educational Background

Pilots who graduated from AABI-Accredited Flight Programs within the past nine years have the highest probability of No Extra Training.

\section{Completions Based on Experience}

Pilots with IA R-ATP Certificates had a higher probability of Completion than pilots with M R-ATP Certificates and Traditional ATP Certificates. Among pilots with Traditional ATP Certificates, pilots with minimum Total Flight Hours (1,500 hours) and a CFI Certificate had the highest probability of Completion.

\section{Extra Training Based on Experience}

Pilots with IA R-ATP Certificates and M R-ATP Certificates had a higher probability of No Extra Training than pilots with Traditional ATP Certificates. Among pilots with Traditional ATP Certificates, pilots with prior Part 121 or military flight experience had the highest probability of No Extra Training.

\section{References}

Aeronautical Experience: Airplane Category Rating, 14 C.F.R. § 61.159 (2015).

Aeronautical Experience: Airplane Category Restricted Privileges, 14 C.F.R. § 61.160 (2015).

Airline Safety and Federal Aviation Administration Extension Act of 2010. Public Law 111-216, 124 Stat, 2348 (2010).

Airline Transport Pilot Certification Training Program, 14 C.F.R. § 121.410 (2015).

Aviation Accreditation Board International (AABI). (2014). Accreditation Criteria Manual: Form 201. Retrieved from http://www.aabi.aero/ forms.html

Aviation Accreditation Board International (AABI). (2016). Summary of recent actions. Retrieved from http://www.aabi.aero/programs.html

Biddix, J. P. (2016). Research rundowns. Retrieved from https://research rundowns.com/

Bjerke, B., Smith, G., Smith, M., Christensen, C., Carney, T., Craig, P., \& Niemczyk, M. (2016). Pilot source study 2015: US regional airline pilot hiring background characteristic changes consequent to Public Law 111-216 and the FAA first officer qualifications rule. Journal of Aviation Technology and Engineering, 5(2), 3-14.

Cortés, A. (2008). Newhire pilot yield: The pilot production pipeline and industry cyclicality. In National Training Aircraft Symposium, Daytona Beach, FL.

Depperschmidt, C. L., Bliss, T. J., \& Casebolt, M. K. (2015). The effect of Public Law 111-216 on collegiate flight programs: Perceptions of aviation faculty and flight center personnel. Collegiate Aviation Review, 33(2), 53-65.

Dismukes, R. K. (2009) Overview of human error. In, R. K. Dismukes (Ed.), Human error in aviation. Aldershot, UK: Ashgate Publishing Limited.

Donoghue, J. A. (2010). Training footprint. Flight Safety Foundation. Retrieved from http://flightsafety.org/aerosafety-world-magazine/ august-2010/training-footprint

Federal Aviation Administration (FAA). (2006). Advanced qualification program (AC 120-54A), Washington, DC: Department of Transportation.

Federal Aviation Administration (FAA). (2010, February 8). New pilot certification requirements for air carrier operations (ANPRM, Docket No. FAA-2010-0100; Notice No. 10-02). Washington, DC: Department of Transportation.
Federal Aviation Administration (FAA). (2012, February 29). Pilot certification and qualification requirements for air carrier operations (NPRM, Docket No. FAA-2010-0100; Notice No. 12-01). Washington, DC: Department of Transportation.

Federal Aviation Administration (FAA). (2013, July 2). Airline transport pilot certification training program (AC 61-138). Washington, DC. Retrieved from http://www.faa.gov/documentlibrary/media/advisory_ circular/ac_61-138.pdf

Federal Aviation Administration (FAA). (2013, July 12). Institution of higher education's application for authority to certify its graduates for an Airline Transport Pilot certificate with reduced aeronautical experience (AC No: 61-139). Washington, DC. Retrieved from http://www.faa.gov/documentLibrary/media/Advisory_Circular/AC_ 61-139.pdf

Federal Aviation Administration (FAA). (2013, July 15). Pilot certification and qualification requirements for air carrier operations; Final rule (Docket No. FAA-2010-0100; Amdt. Nos. 61-130; 121$365 ; 135-127 ; 141-1 ; 142-9)$. Washington, DC: Department of Transportation.

Federal Aviation Administration (FAA). (2014, December 30). Training programs and airman qualifications [FAA Pub 8900.1, CHG 373, Vol 3, Chapter 19]. Retrieved from http://fsims.faa.gov/wdocs/8900.1

Federal Aviation Administration (FAA). (2015a). 14 CFR 121: Subpart N-Training program. Retrieved from http://www.ecfr.gov

Federal Aviation Administration (FAA). (2015b). Advanced qualification program. Retrieved from https://www.faa.gov/training_testing/ training/aqp/

Federal Aviation Administration (FAA). (2015c). Pilot training: ATP certificate. Washington, DC. Retrieved from https://www.faa.gov/ pilots/training/atp/

Laerd Statistics. (2013). One-way ANOVA in SPSS statistics. Retrieved from https://statistics.laerd.com/spss-tutorials/one-way-anova-usingspss-statistics.php

National Transportation Safety Board. (2007a). Aircraft accident report: Crash of Pinnacle Airlines Flight 3701 Bombardier CL-600-2B19, N8396A Jefferson City, Missouri. October 14, 2004 (NTSB/AAR07/01). Washington, DC: National Transportation Safety Board.

National Transportation Safety Board. (2007b). Aircraft accident report: Attempted takeoff from wrong runway Comair Flight 5191 Bombardier CL-600-2B19, N431CA Lexington, Kentucky August 27, 2006. (NTSB/ AAR-07/05). Washington, DC: National Transportation Safety Board. National Transportation Safety Board. (2010). Aircraft accident report: Loss of control on approach Colgan Air, Inc. Operating as Continental 
Connection Flight 3407 Bombardier DHC-8-400, N200WQ Clarence Center, New York February 12, 2009 (NTSB/AAR-10/01). Washington, DC: National Transportation Safety Board.

Operating Experience, Operating Cycles, and Consolidation of Knowledge and Skills, 14 C.F.R. § 121.434 (2015).

Operating Requirements: Domestic, Flag, and Supplemental Operations, 14 C.F.R. § 121 (2015).

Sexton, J. B., \& Klinect, J. R. (2001). The link between safety attitudes and observed performance in flight operations. Retrieved from https:// www.researchgate.net/publication/268001056

Simpson, P. (2014). The mammoth book of air disasters and near misses. Philadelphia, PA: Running Press.

Smith, G. M., Bjerke, E., NewMyer, D. A., Niemczyk, M., \& Hamilton, R. A. (2010). Pilot source study: An analysis of pilot backgrounds and subsequent success in US regional airline training programs. International Journal of Applied Aviation Studies, 10(1), 73-96.

Smith, G. M., Herchko, D., Bjerke, E., Niemczyk, M., Nullmeyer, R., Paasch, J., \& NewMyer, D. A. (2013). The 2012 pilot source study (Phase III): Response to the pilot certification and qualification requirements for air carrier operations. Journal of Aviation Technology and Engineering 2(2), 13-23.

Training Requirements: Airplane Category-Multiengine Class Rating or Airplane Type Rating Concurrently with Airline Transport Pilot Certificate, 14 C.F.R. § 61.156 (2015).

Trusty, J., Thompson, B., \& Petrocelli, J. V. (2004). Practical guide for reporting effect size in quantitative research in the Journal of Counseling \& Development. Journal of Counseling and Development 82(1), 107-111.

Wickens, C.D. (2009). The psychology of aviation surprise: An 8 year update regarding the noticing of black swans [Keynote address]. In, J. Flach \& P. Tsang (Eds.), Proceedings 2009 Symposium on Aviation Psychology: Dayton, OH: Wright State University.

Zaiontz, C. (2016). Effect size for chi-square test. Real statistics using Excel. Retrieved from http://www.real-statistics.com/chi-square-andf-distributions/effect-size-chi-square/

Guy Smith is an associate professor of aeronautical science at EmbryRiddle Aeronautical University in Daytona Beach, FL. He is a 21-year US Navy veteran and spent most of his career on aircraft carriers flying the S-3A Viking. He earned a doctorate in adult and higher education from Montana State University in 1994 and is best known for his research in facilitation teaching methods for adult learners and airline pilot training.
Elizabeth Bjerke currently serves as the chair of the department of aviation at the University of North Dakota in Grand Forks. After receiving her $\mathrm{PhD}$ in educational leadership, her research efforts have focused on student success in collegiate aviation programs, aviation assessment, and accreditation practices, as well as being a researcher on the 2010 and 2012 Pilot Source Studies.

MaryJo Smith is the senior research scientist and CEO of Ypsilon Associates-independent consultants specializing in qualitative and quantitative research and statistical analysis. She earned her $\mathrm{PhD}$ in educational psychology with an emphasis in evaluation, statistics, and research from the University of Minnesota in 1999. In her role as an evaluation consultant, she is the ATQP data manager for two airline consortia in Europe.

Cody Christensen received a doctorate in adult and higher education in 2013 from the University of South Dakota. He is an assistant professor and program coordinator of the aviation program at South Dakota State University in Brookings. His current research involves student safety, financial literacy, and agricultural aviation. He holds an Airline Transport Pilot certificate and was an airline captain for a regional airline before transitioning into academia.

Thomas Carney is a professor of aviation technology at Purdue University in West Lafayette, IN. He has an Airline Transport Pilot certificate with over 48 years of experience as a pilot, and he holds both an $\mathrm{MS}$ and $\mathrm{PhD}$ in atmospheric science. His primary research areas of interest include aviation meteorology, synoptic-scale dynamics and energetics, the use of aircraft for airborne research applications, and pilots' use of weather technology in the cockpit.

Paul Craig earned a doctor of education degree in 1998 and is a professor of aerospace at Middle Tennessee State University in Murfreesboro. He has been the principal investigator on four NASA research grants, including work with computerized flight decks, scenario-based training, team dynamics, and decision-making. He holds the Airline Transport Pilot certificate and is a Gold Seal flight instructor.

Mary Niemczyk is an associate professor and chair of the aviation programs at the Polytechnic School of Arizona State University in Mesa. She has earned a BA in accounting, an MBA-Aviation, and a PhD in learning \& instructional technology. Her research interests center on improving instructional and learning strategies to enhance the performance of individuals in complex, ill-defined environments, such as aviation. 